\title{
A More Efficient Observation Way With Electric Dipole Sources
}

\section{xianxiang wang ( $\nabla$ wangxianxiang09@163.com )}

Jiangxi Engineering Technology Research Center of Nuclear Geoscience Data Science and System, East China University of Technology, Nanchang, 330013, Jiangxi, China https://orcid.org/0000-0001-8224$724 X$

\section{yongbang Chang}

ECUT: East China University of Technology

Juzhi Deng

ECUT: East China University of Technology

\section{Full paper}

Keywords: CSAMT, apparent resistivity definition, a novel exploration, static effect

Posted Date: December 31st, 2020

DOI: https://doi.org/10.21203/rs.3.rs-136038/v1

License: (a) (i) This work is licensed under a Creative Commons Attribution 4.0 International License. Read Full License 


\title{
A more efficient observation way with electric dipole sources
}

\author{
Xian-Xiang Wang *, Yong-bang Chang, Ju-Zhi Deng \\ Jiangxi Engineering Technology Research Center of Nuclear Geoscience Data Science and System, East China University of \\ Technology, Nanchang, 330013, Jiangxi, China
}

\begin{abstract}
The $E_{x}$ and $H_{z}$ amplitude are monotonic functions of the resistivity, and numerical algorithm can be utilized to obtain the high-precision apparent resistivity for all frequencies. On this basis, we focus on the comparative analysis of the resolution for $E_{x}$ field, $H_{z}$ field, and Cagniard apparent resistivity to conductive and resistance targets, which proves that the $E_{x}$ field may have a better resolution for the resistance bodies, and the $H_{z}$ field can better identify the conductive target. Besides, the electromagnetic data is often distorted by the static effect, which seriously affects the application effect of the electromagnetic method. The influence of the static effect on the $E_{x}$ field, $H_{z}$ field, is also analyzed. The apparent resistivity based on the $E_{x}$ field and Cagniard apparent resistivity are severely affected by the static effect which can cover deep anomalous bodies, but the apparent resistivity based on the $H_{z}$ field is almost unaffected by the static effect. At last, a more efficient observation way is provided for the resistance and conductive targets, respectively.
\end{abstract}

Index Terms - CSAMT, apparent resistivity definition, a novel exploration, static effect

\section{INTRODUCTION}

Controlled source audio-frequency magnetotelluric method (CSAMT) is an artificial electromagnetic method that overcomes the shortcomings of source randomness and low signal-to-noise (SNR) in magnetotelluric (MT) method. Orthogonal electric and magnetic fields, generally horizontal electric field $E_{x}$ and horizontal magnetic field $H_{y}$, are measured in CSAMT, to define the Cagniard apparent resistivity similar to MT. It can correctly reflect changes in geoelectric structure along with depth in the far-field zone. In the near-field zone, due to the non-planar wave effect, Cagniard apparent resistivity and phase are severely distorted, which is known as the near-field effect. Apparent resistivity curve rises at $45^{\circ}$, and the phase approaches zero at low frequencies. Both of them are not related to underground electrical structures(Goldstein \& Strangway,1975; Zonge \& Hughes,1991).

Many scholars have proposed a variety of correction methods to solve the near-field effect problem (Kellett et al., 1993; Barte \& Jacobson, 1987; Luan et al., 2018). Some scholars have proposed methods using the inversion with source instead of correction (Routh \& Oldenburg, 1999). Whether corrected or not, Cagniard apparent resistivity can hardly reflect changes in the underground structure in the near-field zone. Therefore, CSAMT data must be collected in the far-field zone. To obtain far-field data, the offset must be large enough to satisfy the plane wave condition. In the artificial source method, the greater the offset, the lower the SNR of the collected data. Besides, with the increase of electromagnetic noise, it is sometimes challenging to collect high-quality CSAMT data in the far-field zone.

In electrical exploration, the significance of apparent resistivity is that we can quickly know about underground structure before inversion. For example, when we conduct field data collection, data collectors can quickly understand the changes in the underground structure through apparent resistivity and evaluate the data. Considering the near-field effect problem caused by the apparent resistivity definition, some

E-Mail: wangxianxiang09@163.com 
scholars have proposed new definition methods of apparent resistivity. Das (1995) defines a precise apparent resistivity using the relationship between the vertical magnetic field and the tangential electric field. However, the disadvantage of this method is that two separate source-receiver configurations must be provided. Van Der et al. (2000) solved this problem by projecting the observation data into a uniform half-space and solving the nonlinear solution. $\mathrm{He}(2017)$ defines an apparent resistivity using the translation algorithm based on the translational effects of resistivity and frequency. However, the above methods are mainly applicable to the magnetic dipole source. Generally, the exploration depth of the electric dipole source is greater than that of the magnetic dipole source, and the layout of the electric dipole source is easier.

The resolution of the electromagnetic method is affected by the source layout and observation components. Many researchers have made lots of attempts to enhance sensitivity(Um, 2007; Chave, 2009; Davydycheva,2011; Fan et al., 2012; Streich, 2016). In order to break through the limitation that the CSAMT method can only be observed in the far-field zone, He et al. (2014, 2015) proposed to observe only the $E_{x}$ field instead of Cagniard apparent resistivity, which can reduces the offset and enhance sensitivity verified by the results of numerical simulation and field observation, and is successfully applied in shale gas exploration( Yuan et al., 2017). Some scholars are employing vertical electric source to obtain the response of deep resistive targets(Holten et al., 2009; Flekkøy et al., 2012; Um, 2012; Tietze et al., 2019 ). The above studies mostly obtained conclusions by directly studying electromagnetic fields. In electromagnetic exploration, apparent resistivity is an essential parameter for providing information about underground electrical structures. This manuscript attempts to compare and analyze the resolution of the different components by studying the apparent resistivity.

The purpose of this manuscript is to define a different apparent resistivity with electric dipole sources and find a better exploration method. Firstly, we analyzes the characteristics of $E_{x}$ and $H_{z}$ generated by electric dipole source and gives the new definition of apparent resistivity based on $E_{x}$ and $H_{z}$, respectively, with the dichotomy method. Then the resolution and static effect of both $E_{x}$ and $H_{z}$ are compared.

\section{THE NEW DEFINITION OF APPARENT RESISTIVITY}

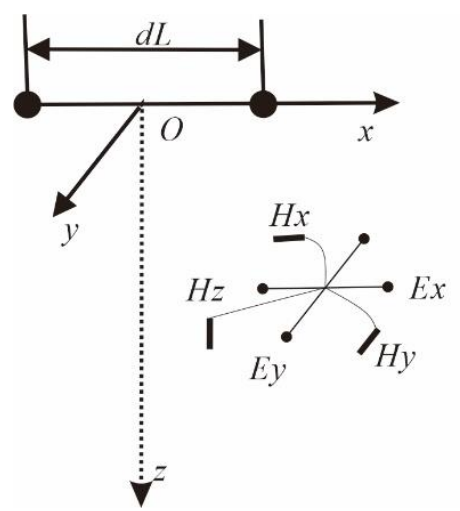

Figure 1. The diagram of horizontal electric dipole source and the coordinate

Suppose there is an electric dipole source on the surface of a uniform half-space. The direction of the $\mathrm{x}$-axis is the direction of the electric dipole, the direction of the z-axis is vertically downward, and the coordinate origin is at the center of the dipole(Figure 1). The current $I_{0} \mathrm{e}^{\mathrm{i} \omega t}$ changes according to the negative harmonic law. The expressions for the $E_{x}$ and $H_{z}$ fields in a homogeneous half-space of resistivity $\rho$ are (Kaufman, A. A., \& Keller, G. V,1983; Nabighian, M. N,1991): 


$$
\begin{aligned}
& E_{x}=\frac{I \rho d L}{2 \pi r^{3}}\left[3 \cos ^{2} \theta-2+e^{i k r}(1-i k r)\right] \\
& H_{y}=\frac{I d L}{2 \pi r^{2}}\left[\left(1-4 \sin ^{2} \varphi\right) I_{1}\left(-\frac{i k r}{2}\right) K_{1}\left(-\frac{i k r}{2}\right)-\frac{i k r}{2} \sin ^{2} \varphi\left(I_{0}\left(-\frac{i k r}{2}\right) K_{1}\left(-\frac{i k r}{2}\right)-I_{1}\left(-\frac{i k r}{2}\right) K_{0}\left(-\frac{i k r}{2}\right)\right)\right] \\
& H_{z}=-\frac{I d L}{2 \pi k^{2} r^{4} \mu \omega} \sin \theta\left[3-e^{i k r}\left(3-3 i k r-k^{2} r^{2}\right)\right]
\end{aligned}
$$

Where the $I_{n}$ and $K_{n}$ represent Bessel functions of the n-th order, $\mu$ is the magnetic permeability, $\omega=2 \pi f$ is the angular frequency, $k=\sqrt{-i \mu \omega / \rho}$ is the wavenumber, $d L$ is the electric dipole length, $r=\sqrt{x^{2}+y^{2}}$ is the distance between the source and the receiver, and $\theta$ is the angle between the receiver direction and the electric dipole source direction. It is observed in the analysis of the Eq. (1) that the $E_{x}, H_{y}$ and $H_{z}$ fields are transcendental functions of resistivity $\rho$, and it is difficult to express the inverse function $\rho\left(E_{x}\right)$ or $\rho\left(H_{z}\right)$ in an explicit relationship. The Cagniard apparent resistivity is approximated by Eq. (1) in the far-field zone and is not applicable to near-field zone. We hope to obtain the apparent resistivity which can be applicable in near-field zone and far-field zone, by solving equation 1 accurately.

Figure 2. The curve of $E_{x}$ and $H_{z}$ fields amplitude with the change of resistivity $\rho$. (a) The curve of $E_{x}$ field amplitude with the change of resistivity $\rho$ (b) The curve of $H_{z}$ field amplitude with the change of resistivity $\rho$

To analyze the relationship between the $E_{x}$ (or $H_{z}$ ) and the resistivity $\rho$, we take the current $I$ as $1 \mathrm{~A}$ and the source length $d L$ as $1 \mathrm{~m}$. The relationship between the $E_{x}$ fields( or $H_{z}$ fields) amplitudes and resistivity $\rho$ is shown in Figure 2 when the offset is $5000 \mathrm{~m}$. As can be seen from Figure 2, $E_{x}$ and $H_{z}$ amplitude are monotonic functions of resistivity $\rho$, so the same field value corresponds to only one
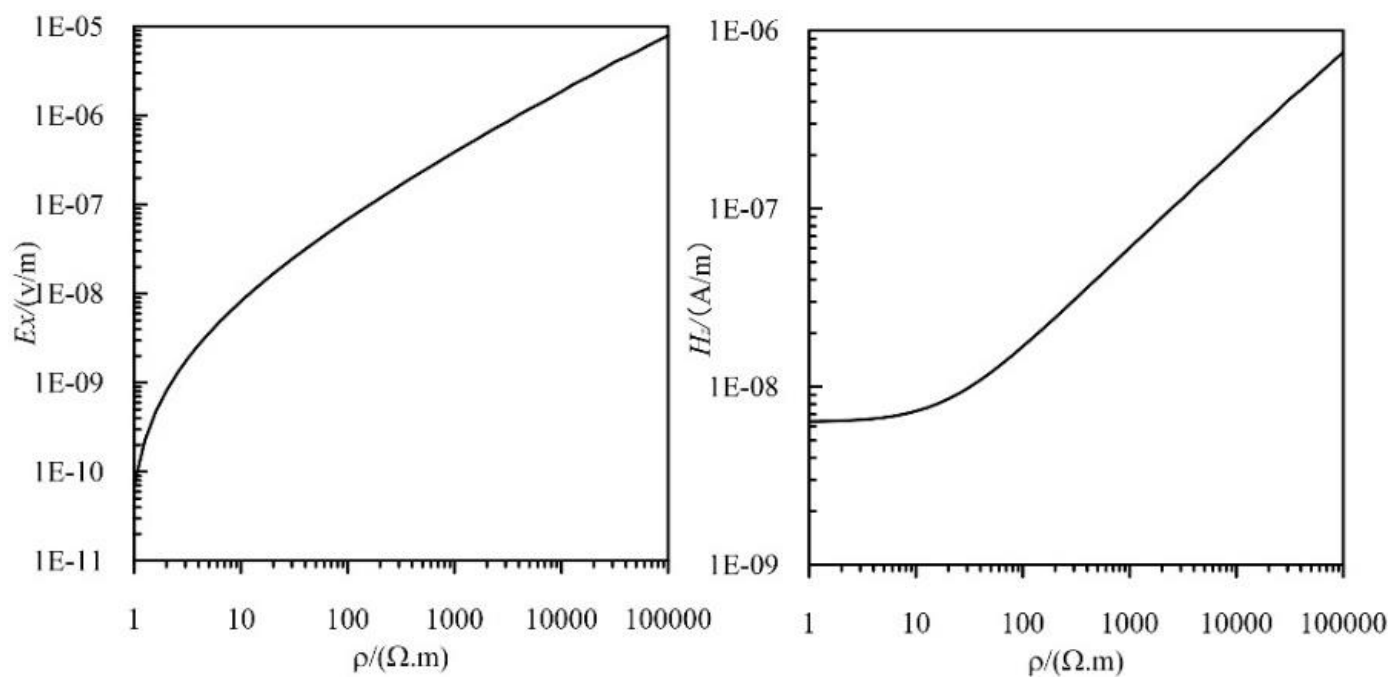

resistivity $\rho$. Although there are many ways to define the apparent resistivity, the essence is to approximate the observed data with a uniform half-space theoretical response using the same observed parameters, of which the resistivity is defined as the apparent resistivity for the observed response. The observation data is substituted into Eq. (1), and the left part is shifted to the right:

$$
\begin{aligned}
& F_{1}(\rho)=\frac{I \rho d L}{2 \pi r^{3}}\left[3 \cos ^{2} \theta-2+e^{i k r}(1-i k r)\right]-E_{x}^{O b s} \\
& F_{2}(\rho)=-\frac{I \rho d L}{2 \pi k^{2} r^{4} \mu \omega} \sin \theta\left[3-e^{i k r}\left(3-3 i k r-k^{2} r^{2}\right)\right]-H_{z}^{O b s}
\end{aligned}
$$

Let the above formulas be zero, and the obtained solution is the apparent resistivity corresponding to the observed data. There are many numerical algorithms that can be used to solve Eq. (2), such as translation 
algorithm, iterative algorithm, dichotomy algorithm and other numerical algorithms. Here we use the dichotomy method to solve the above formulas, which follows the following ideas: for a function $\mathrm{y}=f(\mathrm{x})$ that is continuous on the interval $[\mathrm{a}, \mathrm{b}]$ and $f(\mathrm{a}) . f(\mathrm{~b})<0$, the two endpoints of the interval [a, b] gradually approach the solution by continuously dividing the interval $[a, b]$ into two intervals, and then we can get the approximate value of the solution. The key steps are as follows:

(1) Determine the interval $[a, b]$ and accuracy $\varepsilon$

(2) Find the midpoint $x_{1}$ of the interval $[\mathrm{a}, \mathrm{b}]$

(3) Calculate $F\left(x_{1}\right)$, if $F\left(x_{1}\right)=0, x_{1}$ is the solution of the function

If $F(a) \cdot F\left(x_{1}\right)<0$, let $\mathrm{b}=x_{1} \quad\left(\right.$ the solution $\left.\mathrm{x}_{0} \in\left(\mathrm{a}, x_{1}\right)\right)$

If $F\left(x_{1}\right) \cdot F(b)<0$, let $\mathrm{a}=x_{1} \quad\left(\right.$ the solution $\left.\mathrm{x}_{0} \in\left(x_{1}, \mathrm{~b}\right)\right)$

(4) Determine whether accuracy $\varepsilon$ meets the requirements. That is, if $|(a-b) /(a+b) / 2| /<\varepsilon$, then the approximate solution is $(a+b) / 2$, otherwise repeat $(2) \sim(4)$.

To test the apparent resistivity definition algorithm, we made a 1D model. The model consists of three layers with thicknesses of $300 \mathrm{~m}$ and $500 \mathrm{~m}$, respectively, and the resistivity of $100 \mathrm{ohm}-\mathrm{m}$ and $1000 \mathrm{ohm}-$ $\mathrm{m}, 100 \mathrm{ohm}-\mathrm{m}$, respectively. The offset is $10000 \mathrm{~m}$. When calculating the apparent resistivity, a and $\mathrm{b}$ are taken as $10^{-3}$ and $10^{8}$, respectively, and $\varepsilon$ equals 0.001 . The apparent resistivity curve calculated with the above method is illustrated in Figure 3. By analyzing this figure, it can be seen that the Cagniard apparent resistivity curve can better reflect the change of the underground structure only at high frequencies, and rises at $45^{\circ}$ due to the near-field effect at low frequencies, which is no longer related to the underground structure. The apparent resistivity defined by the $E_{x}$ and $H_{z}$ fields can well reflect the change of the underground structure with depth for all frequencies. At high frequencies, the two curves coincide, and the apparent resistivity is $100 \mathrm{ohm}-\mathrm{m}$ corresponding to the first layer. As the frequency decreases, the exploration depth gradually increases. The apparent resistivity gradually increases, gradually reflecting the middle layer, and then the apparent resistivity gradually goes from high to low, reflecting the third layer. From high frequencies to low frequencies, our apparent resistivity can well reflect the change of the threelayer model from shallow to deep. Built on the above analysis, the apparent resistivity calculated in this paper can truly reflect the change of underground electrical structure, and there is no near-field effect, which can significantly improve the CSAMT resolution.

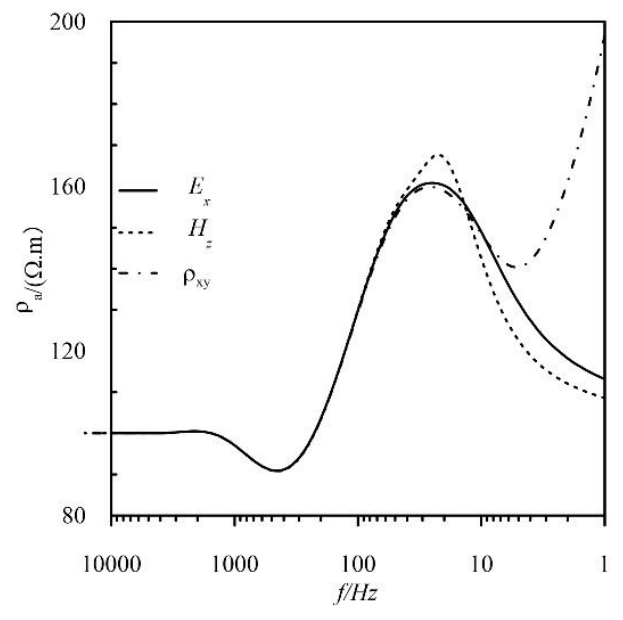

Figure 3. Comparison of apparent resistivity curves defined by different fields 


\section{COMPARATIVE ANALYSIS OF RESOLUTION FOR DIFFERENT COMPONENTS}
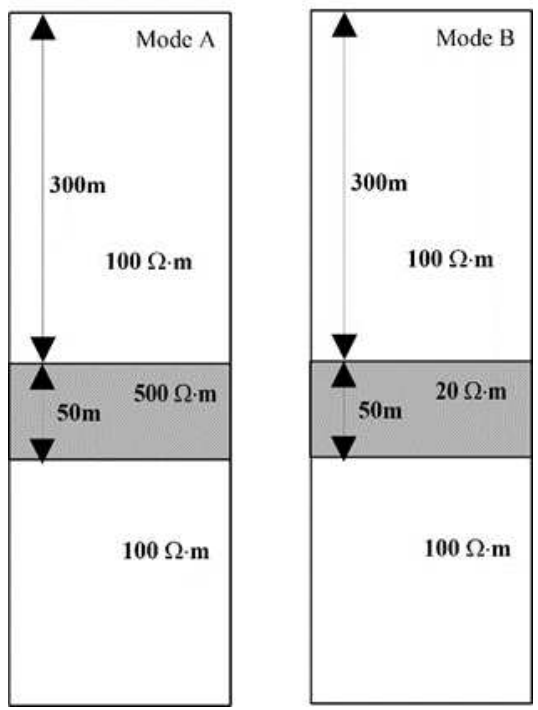

Figure 4. 1D forward model. A three-layer model is used with a thickness of $300 \mathrm{~m}$ and $50 \mathrm{~m}$ respectively, the first and third layer resistivity of $100 \mathrm{ohm}-\mathrm{m}$, and a middle layer resistivity of $500 \mathrm{ohm}-\mathrm{m}$ ( named model A) or $20 \mathrm{ohm}-\mathrm{m}$ (named model B).

The resolution of the electromagnetic method is affected by the observation components. To compare the resolution for different components, a three-layer model is used with a thickness of $300 \mathrm{~m}$ and $50 \mathrm{~m}$ respectively, the first and third layer resistivity of $100 \mathrm{ohm}-\mathrm{m}$, and a middle layer resistivity of $500 \mathrm{ohm}-\mathrm{m}$ ( named model A) or $20 \mathrm{ohm}-\mathrm{m}$ (named model B). The model parameters are presented in Figure 4. For model A, the apparent resistivity curves and pseudo-section for different offsets are given in Figure 5 and Figure 6, respectively. We can find from this figure that the Cagniard apparent resistivity curves are greatly affected by the offsets. When the offsets are small, Cagniard apparent resistivity curves are affected by the near-field effect, which can only reflect the first layer. Only when the offset is large can Cagniard apparent resistivity curves reflect the deep structure. When the offset is $1000 \mathrm{~m}$, the apparent resistivity curve can only reflect the first layer. When the offset is $5000 \mathrm{~m}$, it can only reflect the first and second layer. When the offset is $10000 \mathrm{~m}$, it can better reflect the change of the three-layer structure along with depth change. The extreme value of apparent resistivity is $106.7 \mathrm{ohm}-\mathrm{m}$.

Figure 5(b) and Figure 6(b) show apparent resistivity calculated by the $E_{x}$ field at different offsets. It is evident from the figure that the exploration depth of the $E_{x}$ field is also severely affected by the offset. When the offset is less than $100 \mathrm{~m}$, the apparent resistivity is about $100 \mathrm{ohm}-\mathrm{m}$, which means that the $E_{x}$ field only reflects the shallow electrical structure and is not affected by the deep structure. As the offset increases, the apparent resistivity is still $100 \mathrm{ohm}-\mathrm{m}$ between $2000 \mathrm{~Hz}$ and $10000 \mathrm{~Hz}$, indicating that the $E_{x}$ field at these frequencies mainly reflects the first layer and is not affected by the middle layer. The apparent resistivity is higher than $100 \mathrm{ohm}-\mathrm{m}$ below $2000 \mathrm{~Hz}$, showing that the $E_{x}$ field can well reflect the resistance layer. As the offset increases, the maximum value of apparent resistivity increases gradually. When the offset is $1000 \mathrm{~m}$, we can get the extreme value of $119.3 \mathrm{ohm}-\mathrm{m}$. As the offset increases again, the maximum value becomes smaller. It is because that the $E_{x}$ field is affected by the deep electrical structure, and the proportion of the middle layer in the apparent resistivity is reduced when the offset increases. So the resolution on the resistance layer gets worse when the offset becomes larger again. When the offset is 10000 $\mathrm{m}$, the maximum value is reduced to $106.8 \mathrm{ohm}-\mathrm{m}$. The resolution of the $E_{x}$ field on the resistance layer is not best when the offset is small or large, and the best exploration of the middle high-resistivity layer can 
be obtained only at an appropriate offset. Besides, at the same offset, the exploration depth for the $E_{x}$ field is greater than the CSAMT method.

Figure 5(c) and Figure 6(c) describe apparent resistivity based on the $H_{z}$ field at different offsets. As can be seen from the figure, the exploration depth of $H_{z}$ field is less impacted by the offset. When the offset is expected to be very small, even $10 \mathrm{~m}$, the apparent resistivity curve can well reflect the change of the three-layer electrical structure with depth. At the offset of $10 \mathrm{~m}$, the maximum value of the apparent resistivity is relatively small, about $104.2 \mathrm{ohm}-\mathrm{m}$. As the offset increases, the maximum value becomes larger, suggesting that the resolution on the resistance layer also becomes higher. When the offset is 5000 $\mathrm{m}$, apparent resistivity can achieve the extreme value, to $108.1 \mathrm{ohm}-\mathrm{m}$. This extreme value is significantly lower than the $E_{x}$ field when the offset is appropriate. Depending on the above analysis, the exploration effect of $H_{z}$ field is less affected by the offset. However, the exploration on the resistance layer is not as good as that of the $E_{x}$ field.

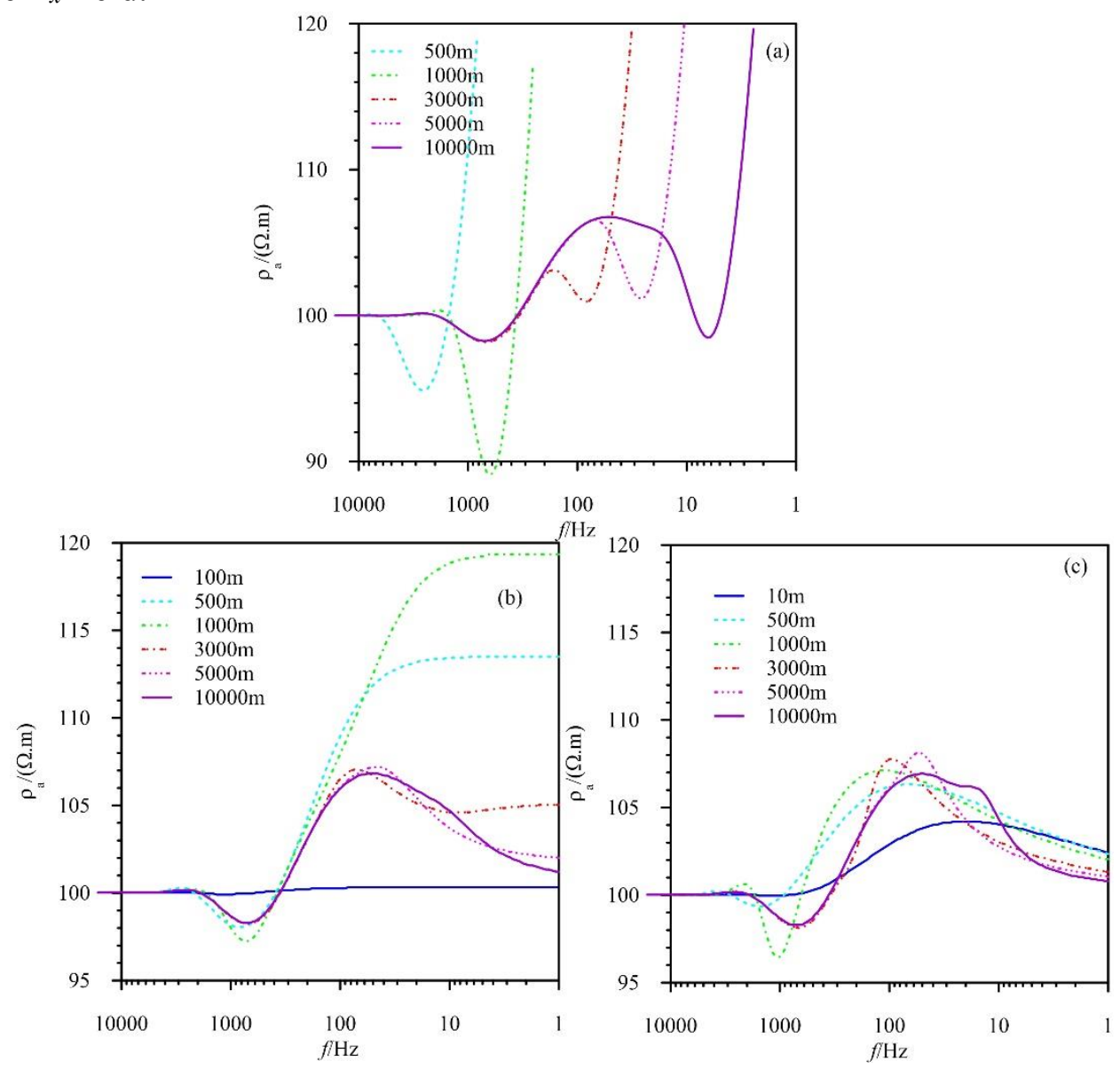

Figure 5. Comparison of different apparent resistivity curves at different offsets when the middle layer is high-resistivity layer (a) Cagniard apparent resistivity curves (b) apparent resistivity curves based on $E_{x}$ field (c) apparent resistivity curves based on $H_{z}$ field 


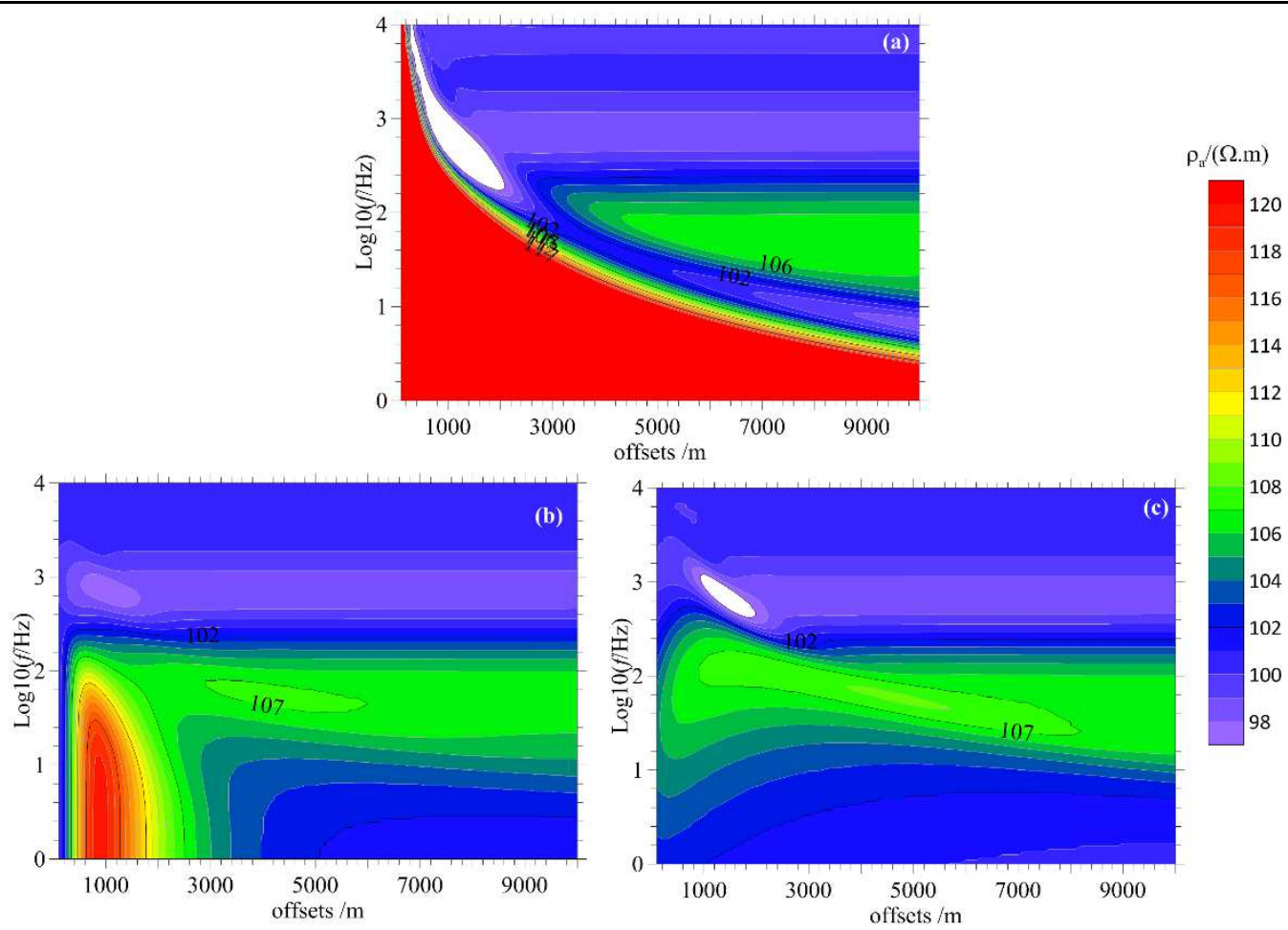

Figure 6. Comparison of apparent resistivity pseudo-section when the middle layer is resistance layer, the x-axis in the figure represents the offset, and the y-axis represents the logarithm of the frequency. (a) Cagniard apparent resistivity pseudo-section (b) apparent resistivity pseudo-section based on $E_{x}$ field (c) apparent resistivity pseudo-section based on $H_{z}$ field.

When the middle layer resistivity in model A is changed to $20 \mathrm{ohm}-\mathrm{m}$, the apparent resistivity curves of $E_{x}$ and $H_{z}$ fields at different offsets are compared, as showed in Figure 7 and Figure 8, respectively. By analyzing these graph, we can conclude that the $E_{x}$ field apparent resistivity curves are also severely affected by the offsets. The apparent resistivity curves under different offsets are different. The minimum value of the apparent resistivity for every offset gradually drops as the offset increases. That is, the resolution on the conductive layer increases as the offset increases, which is different from the model A. When the offset is $5000 \mathrm{~m}$, we can get the extreme value of $74.5 \mathrm{ohm}-\mathrm{m}$. The exploration depth of $H_{z}$ field is also less affected by the offsets as in model A. The deep structure can be detected at a very small offset, and the extreme value of apparent resistivity is about $71.4 \mathrm{ohm}-\mathrm{m}$ at the offset of $5000 \mathrm{~m}$. In a word, the exploration effect of the $H_{z}$ field on the conductive layer is better than that of the $E_{x}$ field, and it can also achieve deep exploration using the small offset, which is a distinct advantage over the $E_{x}$ field. 


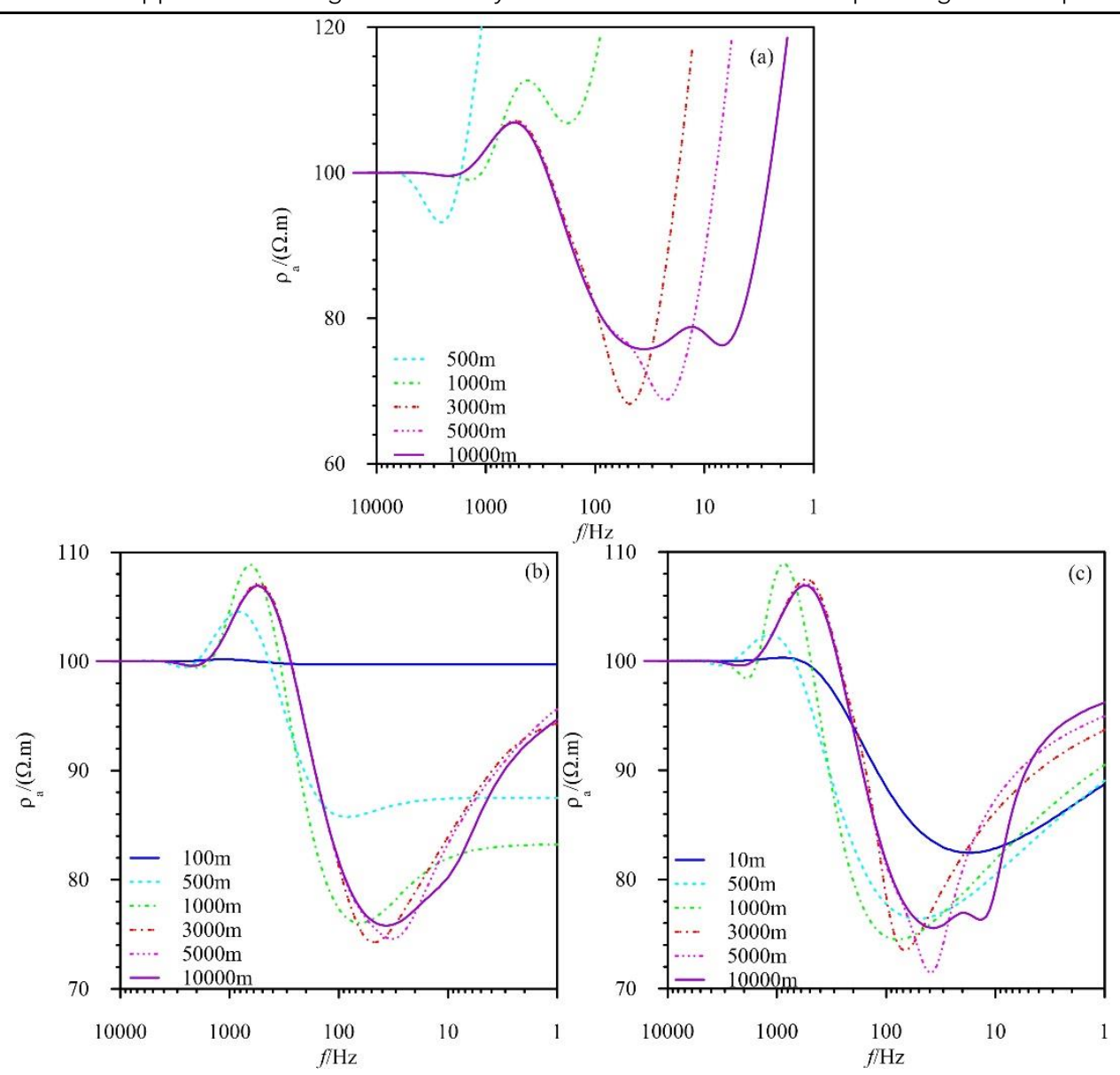

Figure 7. Comparison of different apparent resistivity curves at different offsets when the middle layer is conductive layer (a)Cagniard apparent resistivity curves (b)apparent resistivity curves based on $E_{x}$ field (c) apparent resistivity curves based on $H_{z}$ field

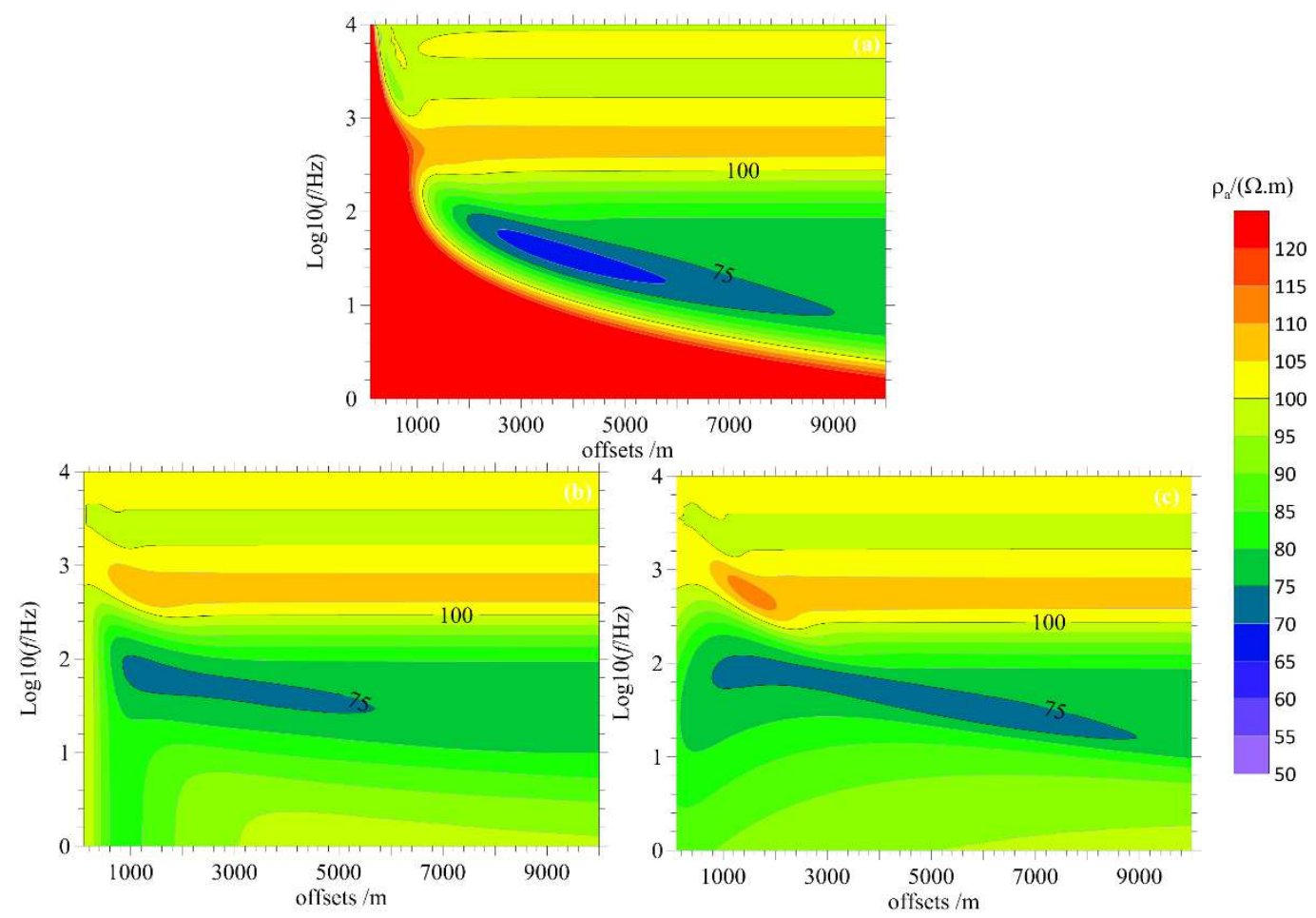

Figure 8. Comparison of apparent resistivity pseudo-section when the middle layer is conductive layer, the $\mathrm{x}$-axis in the figure represents the offset, and the y-axis represents the logarithm of the frequency. (a) Cagniard apparent resistivity 
pseudo-section (b) apparent resistivity pseudo-section based on $E_{x}$ field (c) apparent resistivity pseudo-section based on $H_{z}$ field.

According to the comparison of the 1D numerical simulation results, the exploration effect of the $E_{x}$ field on the resistance layer at the appropriate offset is better than that of the $H_{z}$ field and traditional CSAMT method. The resolution difference on the conductive layer between the $E_{x}$ field, $H_{z}$ field, and traditional CSAMT method is small, and the exploration effect of the $H_{z}$ field is slightly better than the $E_{x}$ field and traditional CSAMT method. Exploration depth of Cagniard apparent resistivity and $E_{x}$ field are significantly affected by the offset, and the $H_{z}$ field is less affected by the offset. To achieve the same depth of exploration, Cagniard apparent resistivity needs the maximum offset, and the $E_{x}$ and $H_{z}$ fields can achieve more considerable depth exploration at a smaller offset. The above studies show that when only the $E_{x}$ or $H_{z}$ field is observed, we can utilize a much smaller offset than the traditional CSAMT for the same target, especially for $H_{z}$. This innovative exploration with smaller offset, can improve the quality of observation data, and reduce the shadow effect as well.

\section{COMPARATIVE ANALYSIS OF STATIC EFFECTS FOR $\boldsymbol{E}_{X}$ AND $\boldsymbol{H}_{Z}$ FIELD}

When shallow structures are inhomogeneous, the electromagnetic data is often distorted by the static effect. It tends to have a steep vertical band with a small lateral extent in the apparent resistivity pseudosection and covers the lower abnormal bodies, which brings significant errors to the data inversion and seriously affects the application effect of the electromagnetic method (EM).

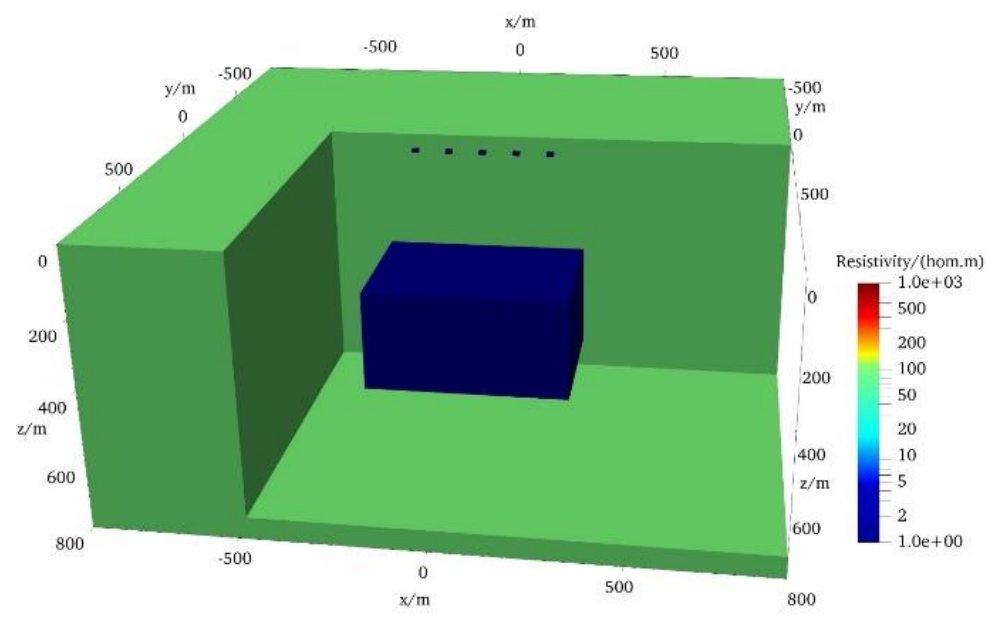

Figure 9. 3D forward model with five anomalies in the shallows

We designed a 3D model to compare the static effects between $E_{x}$ and $H_{z}$ fields. The background model is a homogeneous half-space with a resistivity of $100 \mathrm{ohm}-\mathrm{m}$. An anomalous body is buried in the uniform half-space with a size of $600 \mathrm{~m}^{*} 600 \mathrm{~m} * 300 \mathrm{~m}$, the top depth of $200 \mathrm{~m}$, and the resistivity of $10 \mathrm{ohm}-\mathrm{m}$. Besides, five anomalies were designed in shallow with a size of $20 \mathrm{~m} * 20 \mathrm{~m} * 5 \mathrm{~m}$, the top depth of $5 \mathrm{~m}$, at $200 \mathrm{~m},-100 \mathrm{~m}, 0 \mathrm{~m}, 100 \mathrm{~m}$, and $200 \mathrm{~m}$, respectively. An exploration line is arranged parallel to the source directly above the center of anomalous bodies. The exploration line ranges from $-1000 \mathrm{~m}$ to $1000 \mathrm{~m}$ with $20 \mathrm{~m}$ spacing, and the offset is $10 \mathrm{Km}$. 


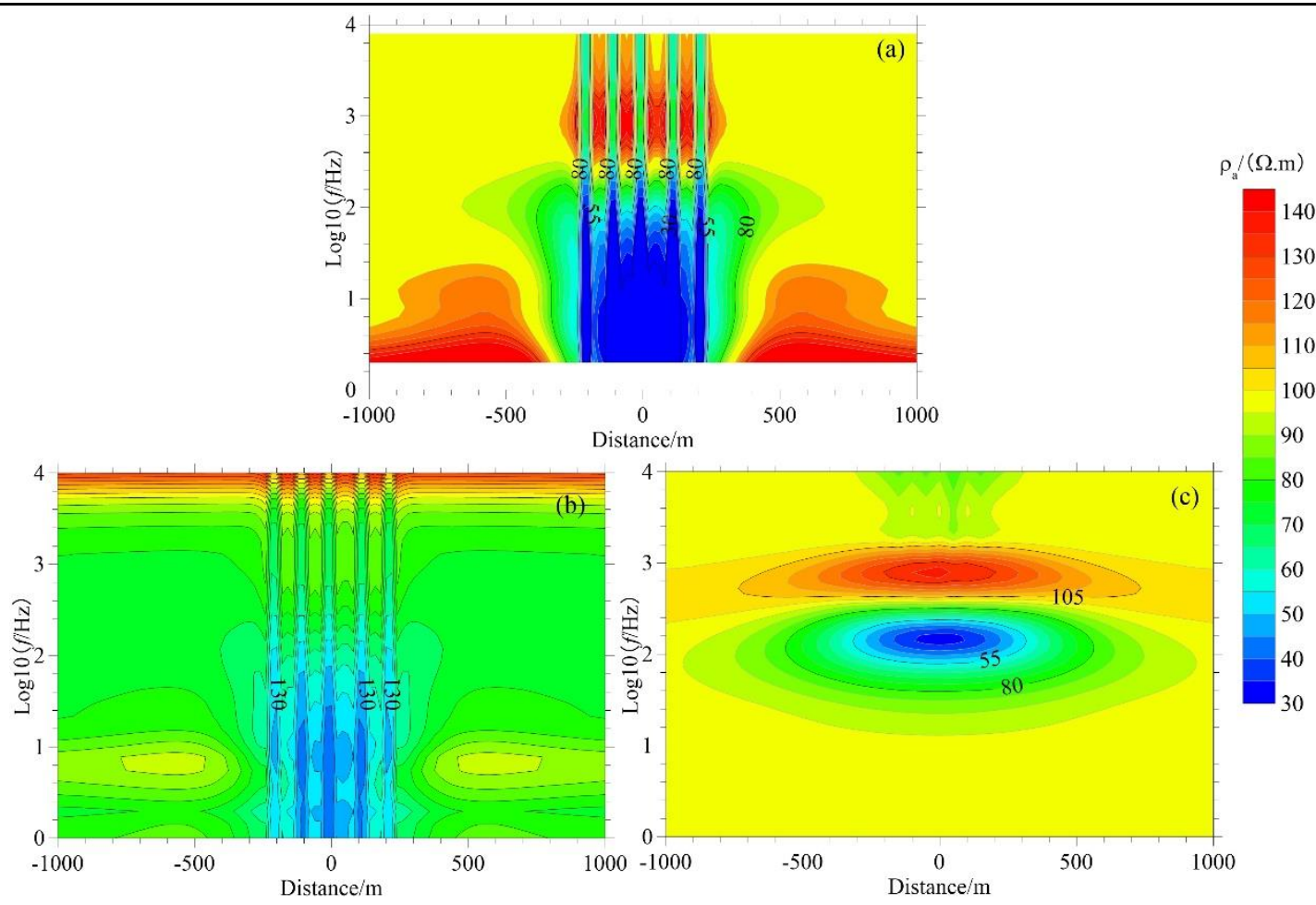

Figure 10. Apparent resistivity pseudo-section based on different fields (a) Cagniard apparent pseudo-section (b) apparent resistivity pseudo-section defined by $E_{x}$ field (c) apparent resistivity pseudo-section defined by $H_{z}$ field.

Figure 10 illustrates apparent resistivity pseudo-section, with Figure 10(a) for Cagniard apparent resistivity, 10(b) for $E_{x}$ field, and 10(c) for $H_{z}$ field. The x-axis in the figure represents the distance, and the $\mathrm{y}$-axis represents the logarithm of the frequency. It is clear from the figure that Cagniard apparent resistivity and the $E_{x}$ field severely affected by static effects. It can be observed in Figure 10(a) and Figure 10(b) that due to the existence of shallow inhomogeneous bodies, the steep contours appear at the $-200 \mathrm{~m},-100 \mathrm{~m}, 0$ m, $100 \mathrm{~m}, 200 \mathrm{~m}$, respectively. The deep low-resistivity body is integrated with shallow abnormal bodies and cannot be differentiated. In Figure 10(c), there is no steep vertical contour. The shallow anomaly only affects the high-frequency data and has no impact on the low-frequency data. Besides, the deep anomaly only has an impact on the data at the corresponding frequencies. In short, the $H_{z}$ field is hardly affected by static effects, which is different from Cagniard apparent resistivity and $E_{x}$ field. 

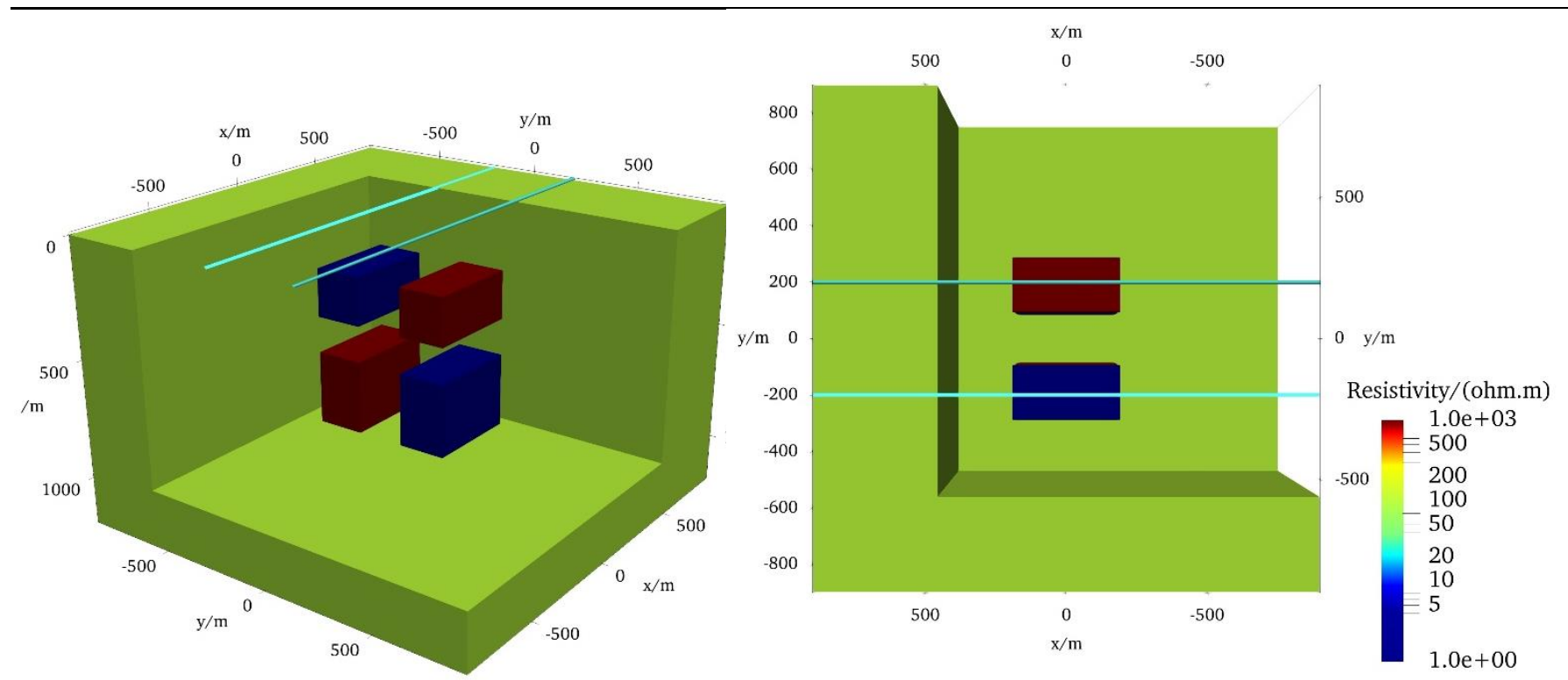

Figure 11. A more complex 3D forward model. The four anomalies are divided into conductive and resistance bodies, of which red represents resistance bodies with a resistivity of $1000 \mathrm{ohm} . \mathrm{m}$, and blue represents conductive bodies with a resistivity of 10 ohm.m. The cyan lines are the designed exploration lines, which just pass through the center of the anomalous bodies.

Shallow anomalous bodies can not only cause static effects, but they can also cover deep anomalous bodies. We designed a more complex 3D model. The background resistivity is $100 \Omega \cdot m$. There are four anomalous bodies in the model, which are distributed in two layers, two anomalous bodies in each layer, as shown in Figure 11. The length of all anomalies in the x-directions is $400 \mathrm{~m}$, and the length of all anomalies in the y-directions is $200 \mathrm{~m}$. The top plates of the two anomaly bodies in the first layer are 200 $\mathrm{m}$, and their thickness is $100 \mathrm{~m}$. The top plates of the four anomaly bodies in the second layer are $550 \mathrm{~m}$, and their thickness is $300 \mathrm{~m}$. The four anomalies are divided into conductive and resistance bodies, of which red represents resistance bodies with a resistivity of $1000 \Omega \cdot m$, and blue represents conductive bodies with a resistivity of $10 \Omega \cdot m$.

In order to compare the resolution of the $E_{x}$ field and the $H_{z}$ field, we designed two exploration lines, which are above the center of the anomalous bodies (Figure 11). Figure 12 described the apparent resistivity pseudo-section of the two lines. When the shallow anomalous body is conductive and the deep is resistance, the apparent resistivity of $H_{z}$ field from $100 \mathrm{~Hz}$ to $1000 \mathrm{~Hz}$ is significantly low, which proves the existence of the conductive body, and it is high at low frequencies, demonstrating the presence of resistance body (Figure 12c). In the Ex pseudo-section, the apparent resistivity is low from $0.1 \mathrm{~Hz}$ to $400 \mathrm{~Hz}$, which illustrates that the shallow conductive body masks the deep resistance body and cannot reflect its existence (Figure 12a). When there is a high-resistance body in the shallow, the $\mathrm{Hz}$ field still can distinguish the shallow resistance body from the deep conductive body(Figure 12d). In the Ex field pseudo-section, there are no obvious abnormalities at high frequencies, while the apparent resistivity from $0.1 \mathrm{~Hz}$ to $100 \mathrm{~Hz}$ is lower which reflects the deep conductive body (Figure 12c). 


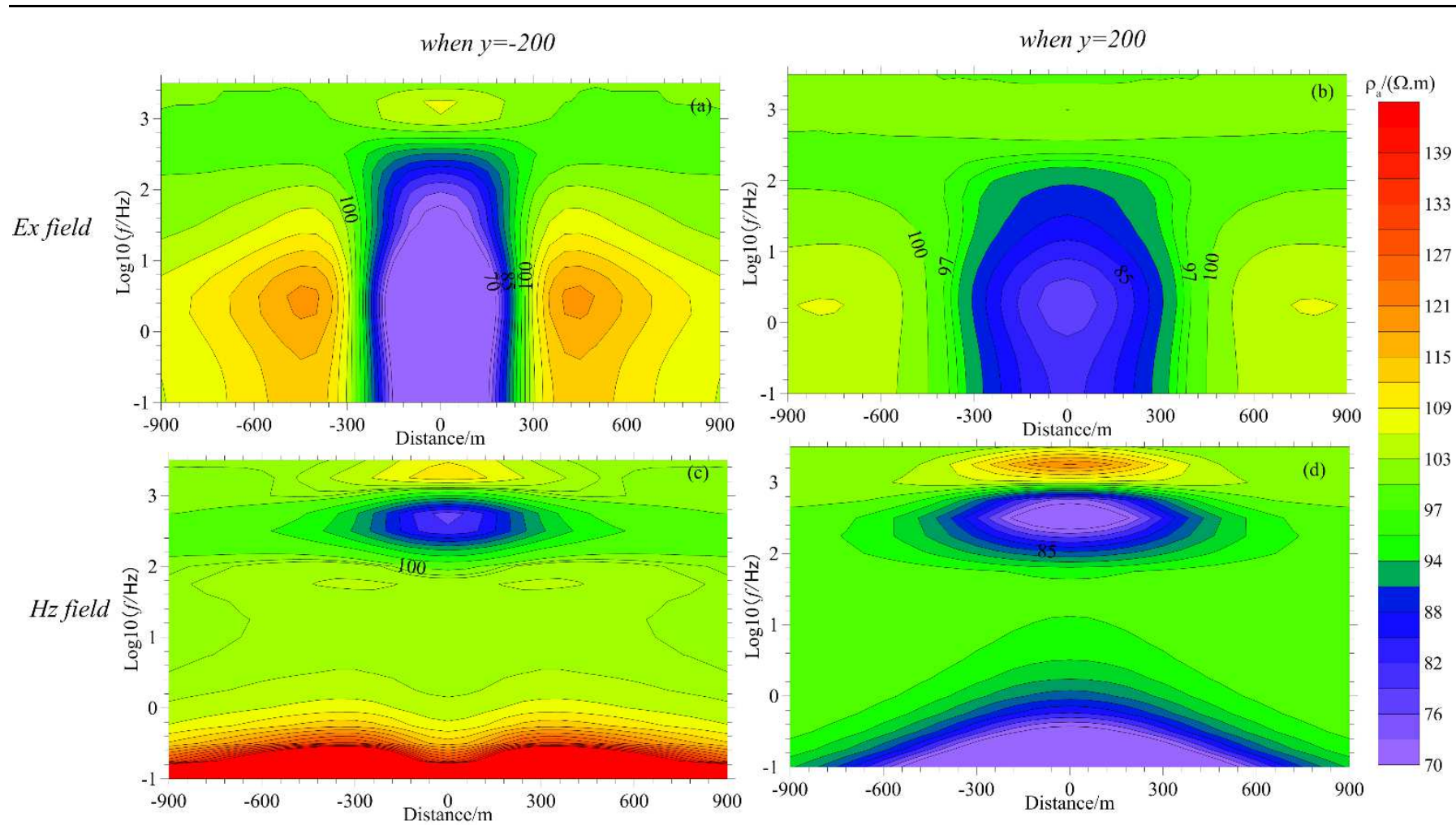

Figure 12. Apparent resistivity pseudo-section for both the $E x$ field and $H_{z}$ field. The first row: $E_{x}$ field, the second row: $H_{z}$ field. The first column: $\mathrm{y}=-200 \mathrm{~m}$, the second column: $\mathrm{y}=200 \mathrm{~m}$.

Besides, we performed a 3D inversion based on the $E_{x}$ data using the code developed by the Consortium for Electromagnetic Modeling (Gribenko \& Zhdanov, 2007). In order to complete the 3D inversion, there are 19 survey lines with $100 \mathrm{~m}$ spacing and 37 exploration points on each line with $50 \mathrm{~m}$ spacing. Figure 13 illustrates the 3D inversion results based on the $E_{x}$ field. As can be seen from the figure, inversion results can recover the distribution range and true resistivity of conductive bodies very well. However, it is difficult to restore the deep resistance target, above which there is a conductive body that masks the deep resistance target and affects the exploration.

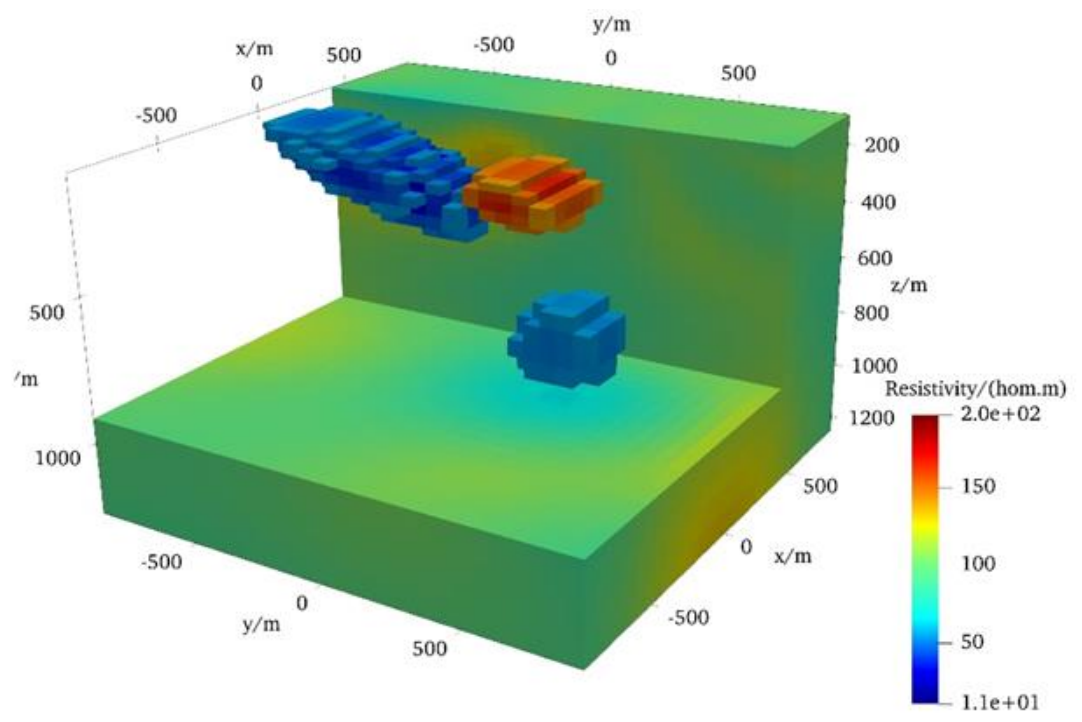

Figure 13. Slices of the recovered model from the 3D inversion of $E x$ field

According to the above analysis, when the geological structure is complex, and there are conductive and resistance bodies in the same area, for the Ex field, the shallow conductive bodies may mask the deep 
resistance bodies, while the shallow resistance body cannot cover the deep conductive bodies. Because the $\mathrm{Hz}$ field is hardly affected by static effects, shallow anomalous does not cover up deep anomalous bodies. Therefore, the $H_{z}$ field may be more suitable than Ex field when the targets are complex.

\section{CONCLUSIONS}

In this paper, a novel method for gaining the apparent resistivity is given with a numerical method. According to the monotonicity of the $E_{x}$ and $H_{z}$ fields, the apparent resistivity for each component is generated with the dichotomy method. The calculation of the numerical model proves the correctness and effectiveness of the method. Besides, the apparent resistivity defined by this manuscript can significantly improve the near-field effect compared to the Cagniard apparent resistivity.

The research on the resolution of the conductive and resistance layers by $E_{x}$ field, $H_{z}$ field, and Cagniard apparent resistivity shows the Cagniard apparent resistivity and $E_{x}$ field are affected by the offset, and the $H_{z}$ field is less affected by the offset. To complete the same exploration depth, Cagniard apparent resistivity requires the maximum offset. $E_{x}$ and $H_{z}$ fields can achieve considerable depth exploration at a small offset, which provides a novel exploration for deep electrical structures. The $E_{x}$ field resolution on the resistance body is better than that of the $H_{z}$ field and traditional CSAMT method. The $H_{z}$ field resolution on the conductive target is slightly better than the $E_{x}$ field. Unfortunately, Cagniard apparent resistivity and $E_{x}$ field are severely affected by static effects, which make it difficult to interpret the EM data. However, the $H_{z}$ field is hardly affected by static effects and can be measured without grounding, which is more suitable for areas with difficult groundings, such as the desert, frozen soil area. In a word, the $E_{x}$ field may be the better choice than $H_{z}$ field when detecting resistance bodies, and the $H_{z}$ field may be a better one when looking for conductive bodies. Moreover, $H_{z}$ field may be more suitable for the detection of complex geological bodies.

\section{AVAilability OF DATA AND MATERIALS}

The data that support the findings of this study are available upon request from the corresponding author.

\section{COMPETING INTERESTS}

The authors declare that they have no competing financial interests.

\section{FUNDING}

The study was supported by the National Natural Science Foundation of China (Grant number: 4141964006, 4141964003), jiangxi Provincial Natural Science Foundation(20202BABL201026 and 20202BAB201013).

\section{ACKNOWLEDGEMENTS}

Not applicable.

\section{AUTHORS' CONTRIBUTIONS}

XW carried out the data processing, and drafted the manuscript. CB and JD helped draft the manuscript. All authors read and approved the final manuscript.

\section{REFERENCES}


Bartel, L. C., \& Jacobson, R. D.1987. Results of a controlled-source audiofrequency magnetotelluric survey at the Puhimau thermal area, Kilauea Volcano, Hawaii. Geophysics, 52(5), 665-677.

Boerner, David E., Ron D. Kurtz, and Alan G. Jones. "Orthogonality in CSAMT and MT measurements." Geophysics 58.7 (1993): 924-934.

Chave, A. D. 2009. On the electromagnetic fields produced by marine frequency domain controlled sources. Geophysical Journal International, 179(3), 1429-1457.

Das, U. C.1995. Apparent resistivity curves in controlled-source electromagnetic sounding directly reflecting true resistivities in a layered earth. Geophysics, 60(1), 53-60.

Davydycheva, S., \& Rykhlinski, N. 2011. Focused-source electromagnetic survey versus standard CSEM: 3D modeling in complex geometries. Geophysics, 76(1), F27-F41.

Fan, Y., Snieder, R., Slob, E., Hunziker, J., Singer, J., Sheiman, J., \& Rosenquist, M. 2012. Increasing the sensitivity of controlled-source electromagnetics with synthetic aperture. Geophysics, 77(2), E135-E145.

Flekkøy, E. G., Håland, E., \& Måløy, K. J. 2012. Comparison of the low-frequency variations of the vertical and horizontal components of the electric background field at the sea bottom. Geophysics, 77(6), E391-E396.

Goldstein, M. A., \& Strangway, D. W. 1975. Audio-frequency magnetotellurics with a grounded electric dipole source. Geophysics, 40(4), 669-683.

He, X., Wang, H., \& Ma, S. 2017. Translation algorithm of the apparent conductivity using the frequency-domain electromagnetic method of a magnetic dipole. Journal of Applied Geophysics, 146, 221-227.

He, J., Li, D., Dai, S. 2014. Shale gas detection with wide field electromagnetic method in North-western Hunan. Oil Geophysical Prospecting (in Chinese), 49(5), 1006-1012.

He, J. 2015. Wide field electromagnetic methods. In SEG Technical Program Expanded Abstracts 2015 (pp. 1006-1011). Society of Exploration Geophysicists.

Holten, T., Flekkøy, E. G., Singer, B., Blixt, E. M., Hanssen, A., \& Måløy, K. J. 2009. Vertical source, vertical receiver, electromagnetic technique for offshore hydrocarbon exploration. first break, 27(5).

Kellett, R., Bishop, J., \& Van Reed, E. 1993. The effects of source polarization in CSAMT data over two massive sulfide deposits in Australia. Geophysics, 58(12), 1764-1772.

Kaufman, A. A., \& Keller, G. V. 1983. Frequency and transient soundings. Chi-Yu King Roberto Scarpa, 207.

Luan X. D., Di Q. Y., Lei D. 2018. Near-field correction of CSAMT data based on Newton iteration method and GA method. CHINESE JOURNAL OF GEOPHYSICS-CHINESE EDITION, 61(10), 4148-4159.

Nabighian, M. N. 1991. Electromagnetic Methods in Applied Geophysics: Volume 2, Application, Parts A and B: Volume 2, Application, Parts A and B. Society of Exploration Geophysicists.

Routh, P. S., \& Oldenburg, D. W. 1999. Inversion of controlled source audio-frequency magnetotellurics data for a horizontally layered earth. Geophysics, 64(6), 1689-1697.

Streich, R. 2016. Controlled-source electromagnetic approaches for hydrocarbon exploration and monitoring on land. Surveys in geophysics, 37(1), 47-80.

Tietze, K., Ritter, O., Patzer, C., Veeken, P., \& Dillen, M. 2019. Repeatability of land-based controlled-source electromagnetic measurements in industrialized areas and including vertical electric fields. Geophysical Journal International, 218(3), 1552-1571.

Um, E. S., \& Alumbaugh, D. L. 2007. On the physics of the marine controlled-source electromagnetic method. geophysics, 72(2), WA13-WA26.

Um, E. S., Alumbaugh, D. L., Harris, J. M., \& Chen, J. 2012. Numerical modeling analysis of short-offset electric-field measurements with a vertical electric dipole source in complex offshore environments. Geophysics, 77(5), E329E341.

Van Der Kruk, J., Meekes, J. A. C., Van Den Berg, P. M., \& Fokkema, J. T. 2000. An apparent - resistivity concept for 
low - frequency electromagnetic sounding techniques. Geophysical Prospecting, 48(6), 1033-1052.

Yuan, B., Li, D., \& Bayless, R. C. 2017. Wide field electromagnetic method for shale gas exploration in southern China: A case study. Journal of Environmental and Engineering Geophysics, 22(3), 279-289.

Zhou, H., Yao, Y., Liu, C., Lin, J., Kang, L., Li, G., \& Zeng, X. 2018. Feasibility of signal enhancement with multiple grounded - wire sources for a frequency - domain electromagnetic survey. Geophysical Prospecting, 66(4), 818-832.

Zonge, K. L., \& Hughes, L. J. 1991. Controlled source audio-frequency magnetotellurics. In Electromagnetic Methods in Applied Geophysics: Volume 2, Application, Parts A and B(pp. 713-810). Society of Exploration Geophysicists. 
Figures

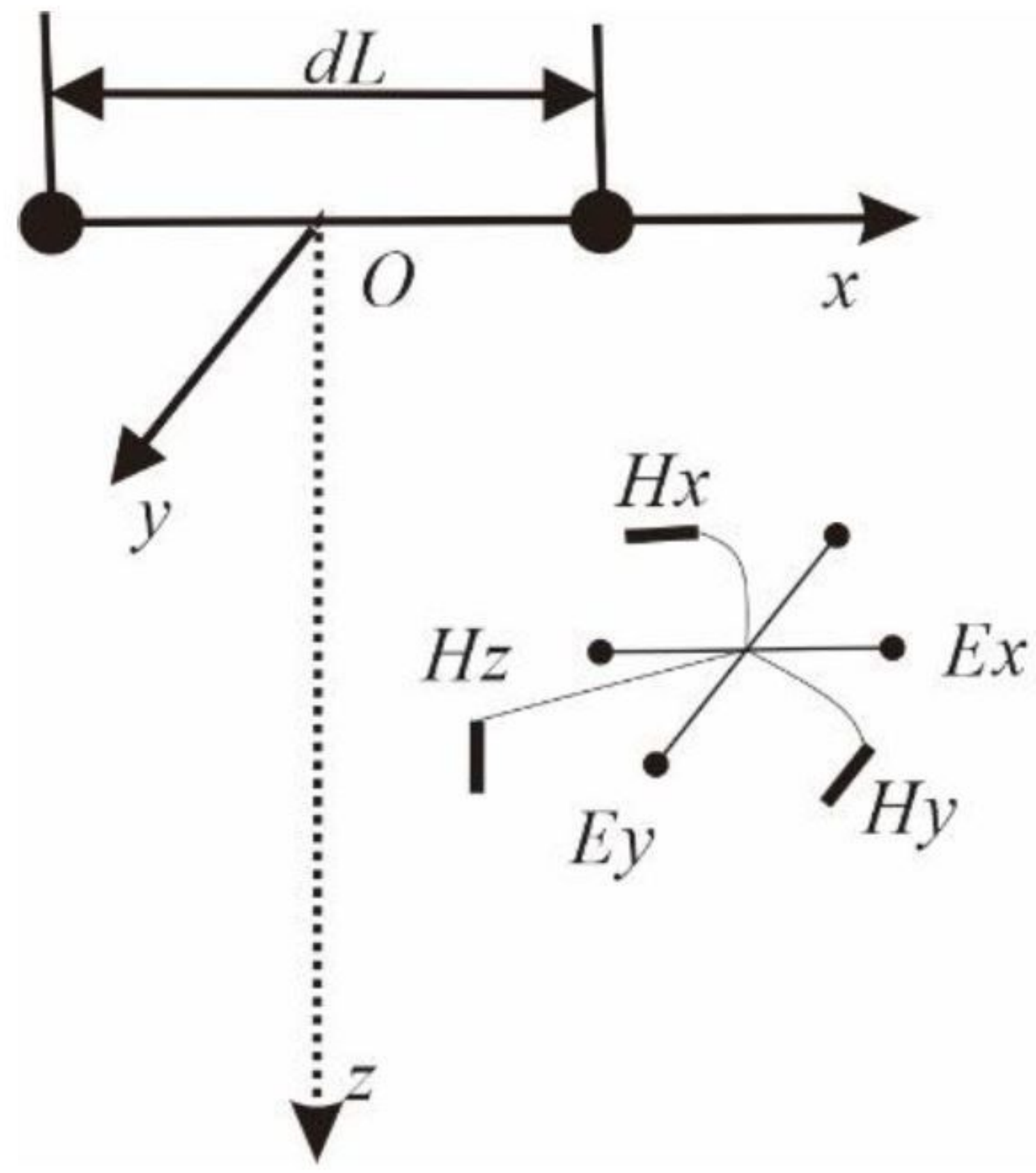

Figure 1

The diagram of horizontal electric dipole source and the coordinate 

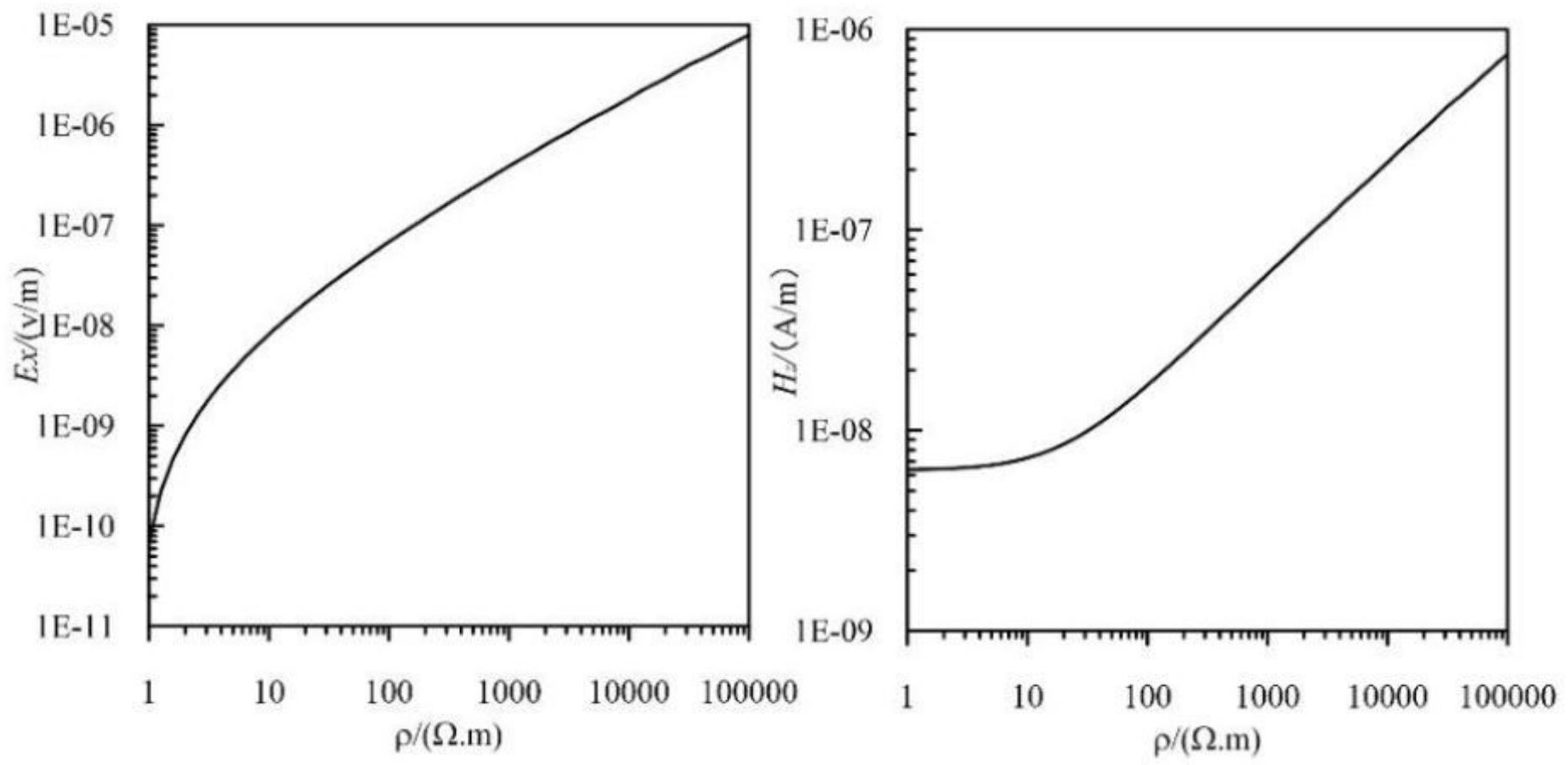

Figure 2

The relationship between the Ex fields( or $\mathrm{Hz}$ fields) amplitudes and resistivity $\rho$ is shown in Figure 2 


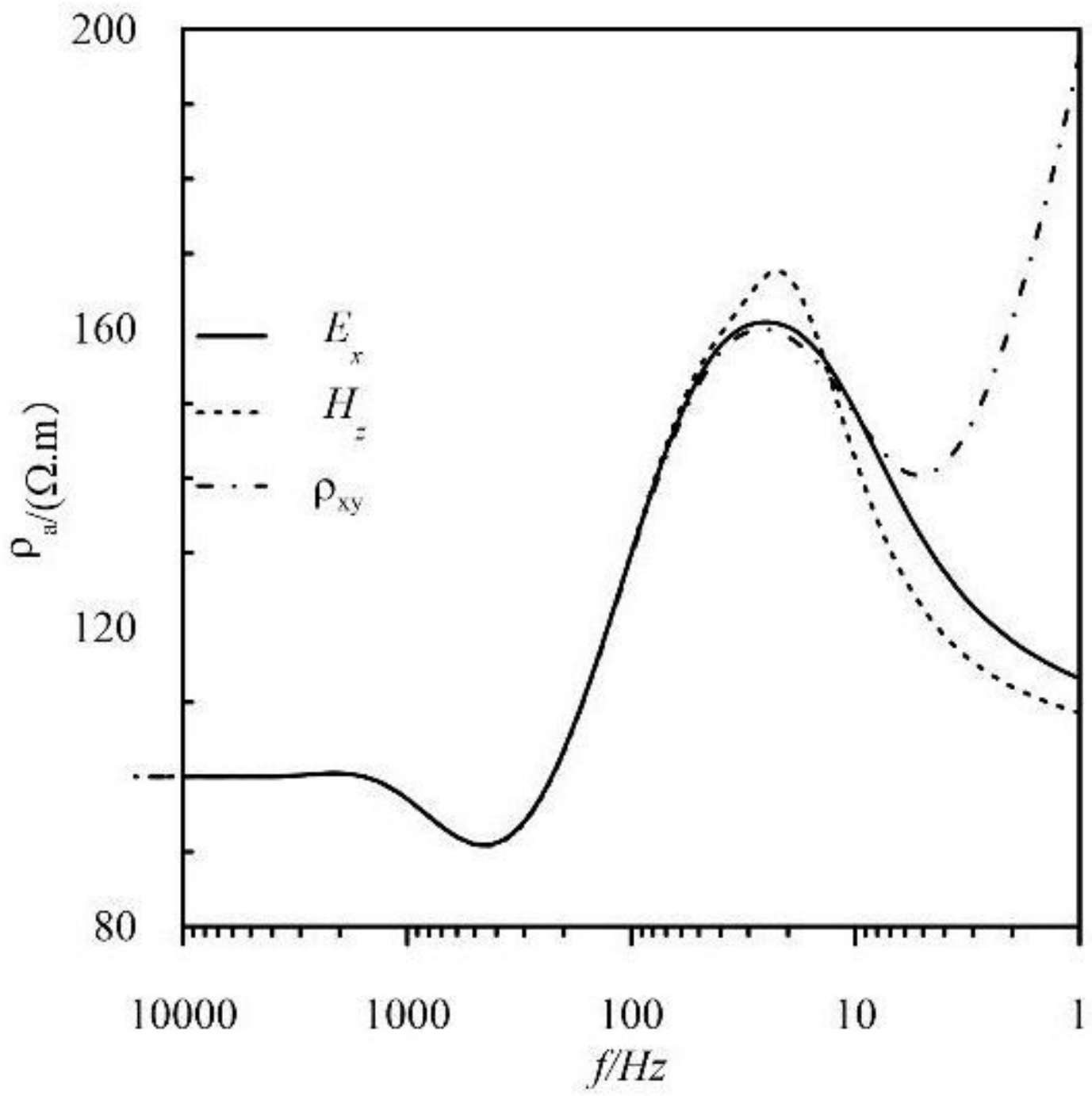

Figure 3

Comparison of apparent resistivity curves defined by different fields 

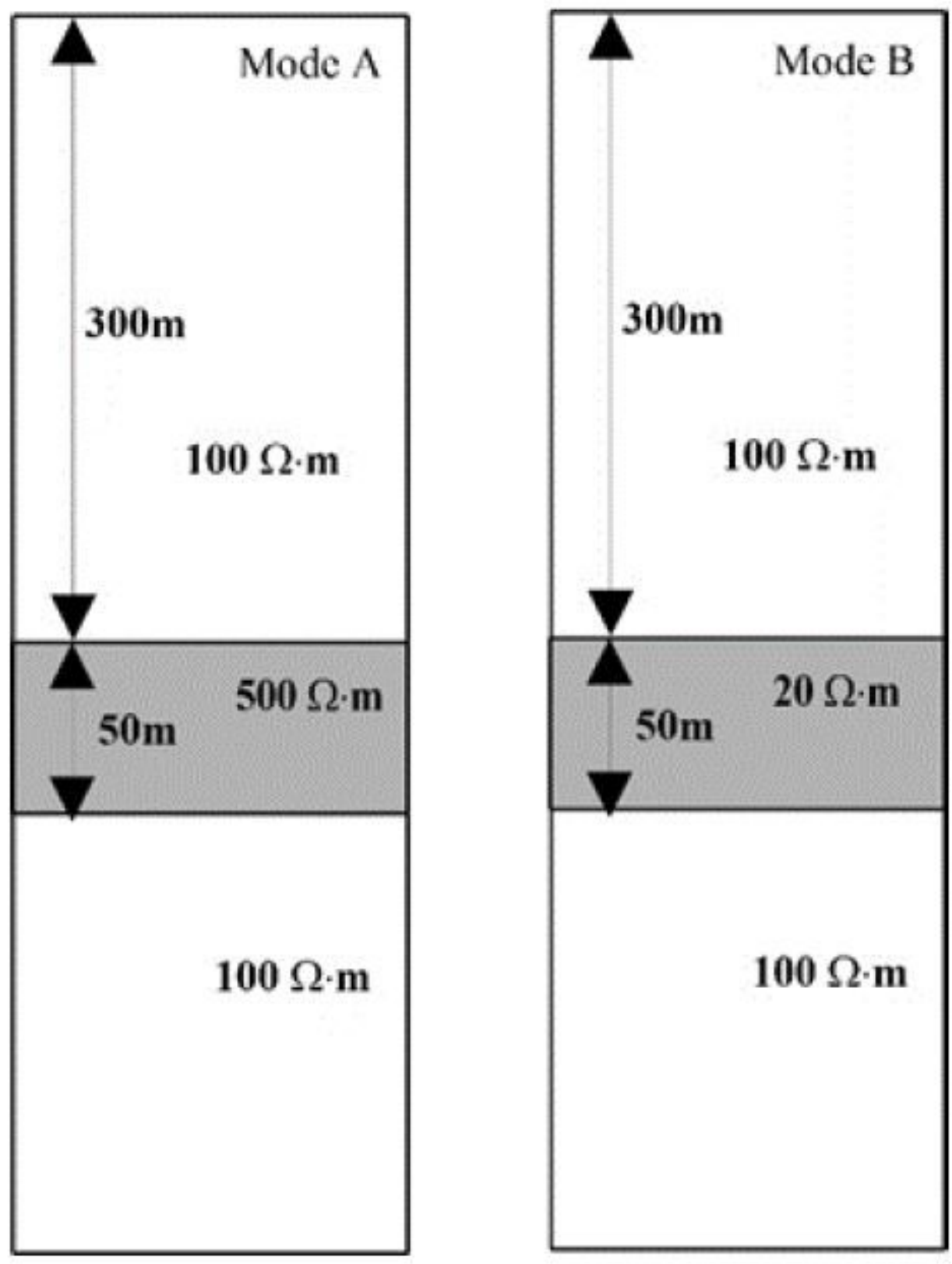

Figure 4

1D forward model. A three-layer model is used with a thickness of $300 \mathrm{~m}$ and $50 \mathrm{~m}$ respectively, the first and third layer resistivity of $100 \mathrm{ohm}-\mathrm{m}$, and a middle layer resistivity of $500 \mathrm{ohm}-\mathrm{m}$ ( named model A) or 20 ohm-m (named model B). 


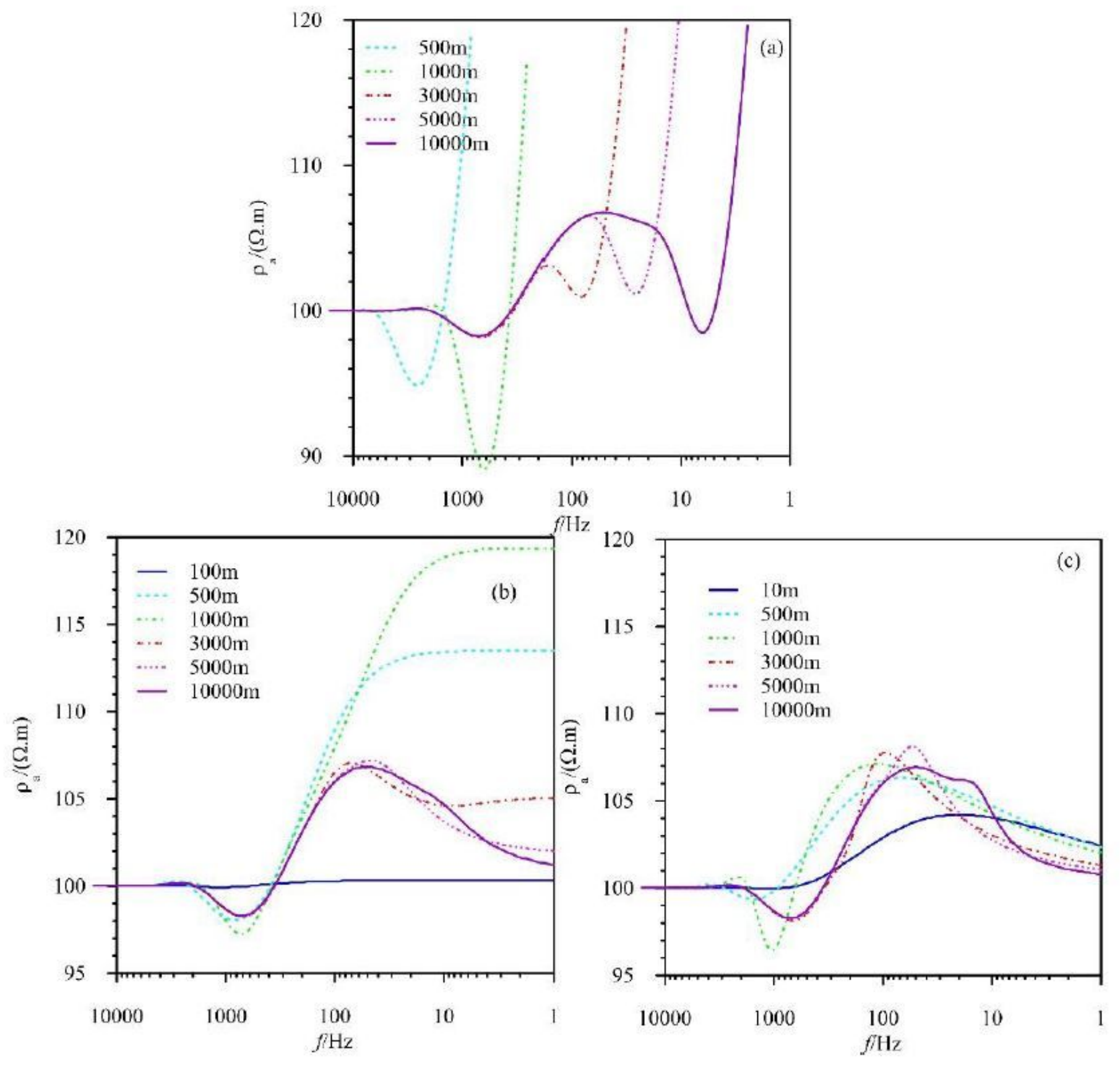

Figure 5

Comparison of different apparent resistivity curves at different offsets when the middle layer is highresistivity layer (a) Cagniard apparent resistivity curves (b) apparent resistivity curves based on Ex field (c) apparent resistivity curves based on $\mathrm{Hz}$ field 


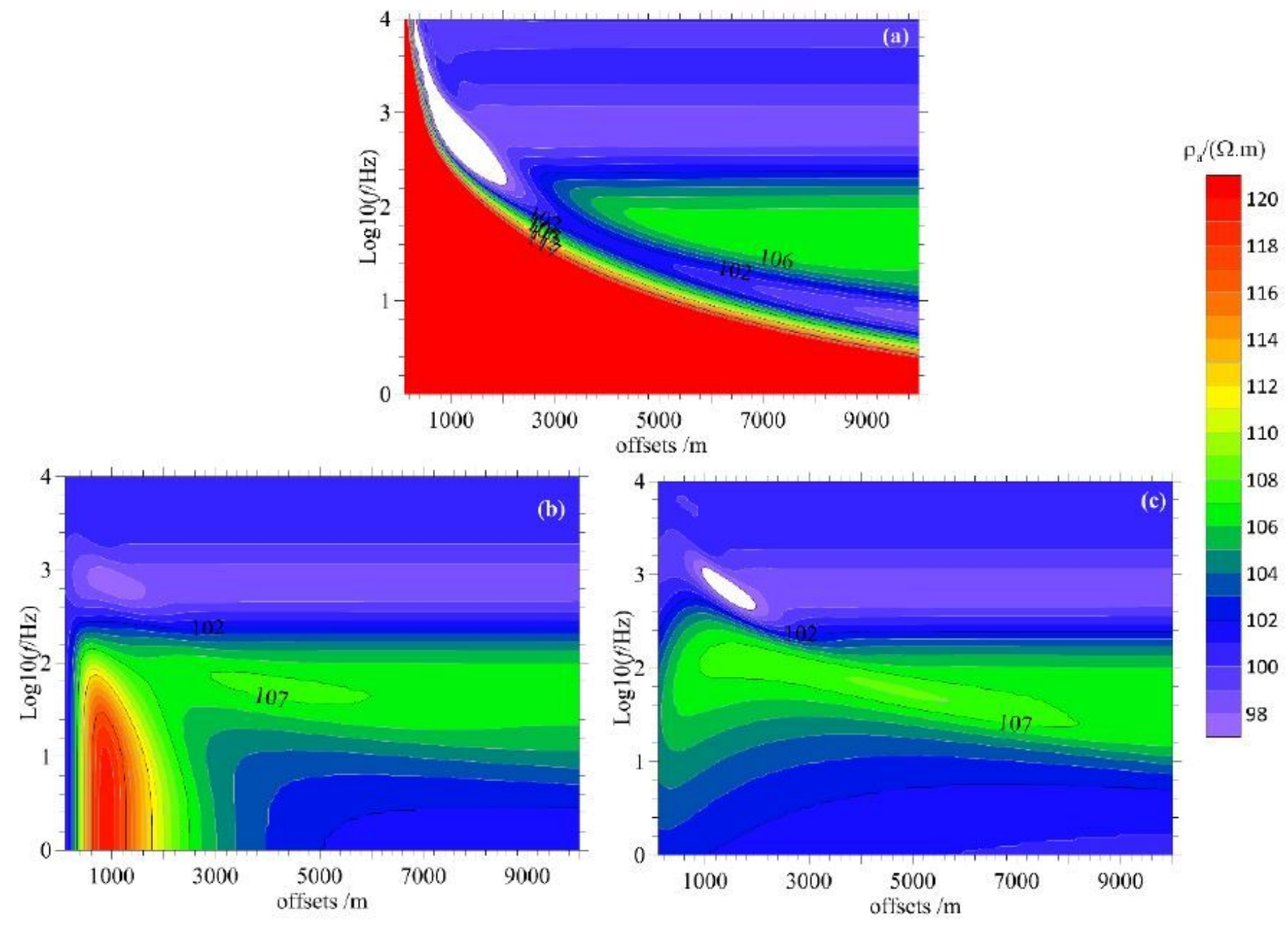

Figure 6

Comparison of apparent resistivity pseudo-section when the middle layer is resistance layer, the $x$-axis in the figure represents the offset, and the y-axis represents the logarithm of the frequency. (a) Cagniard apparent resistivity pseudo-section (b) apparent resistivity pseudo-section based on Ex field (c) apparent resistivity pseudo-section based on $\mathrm{Hz}$ field. 

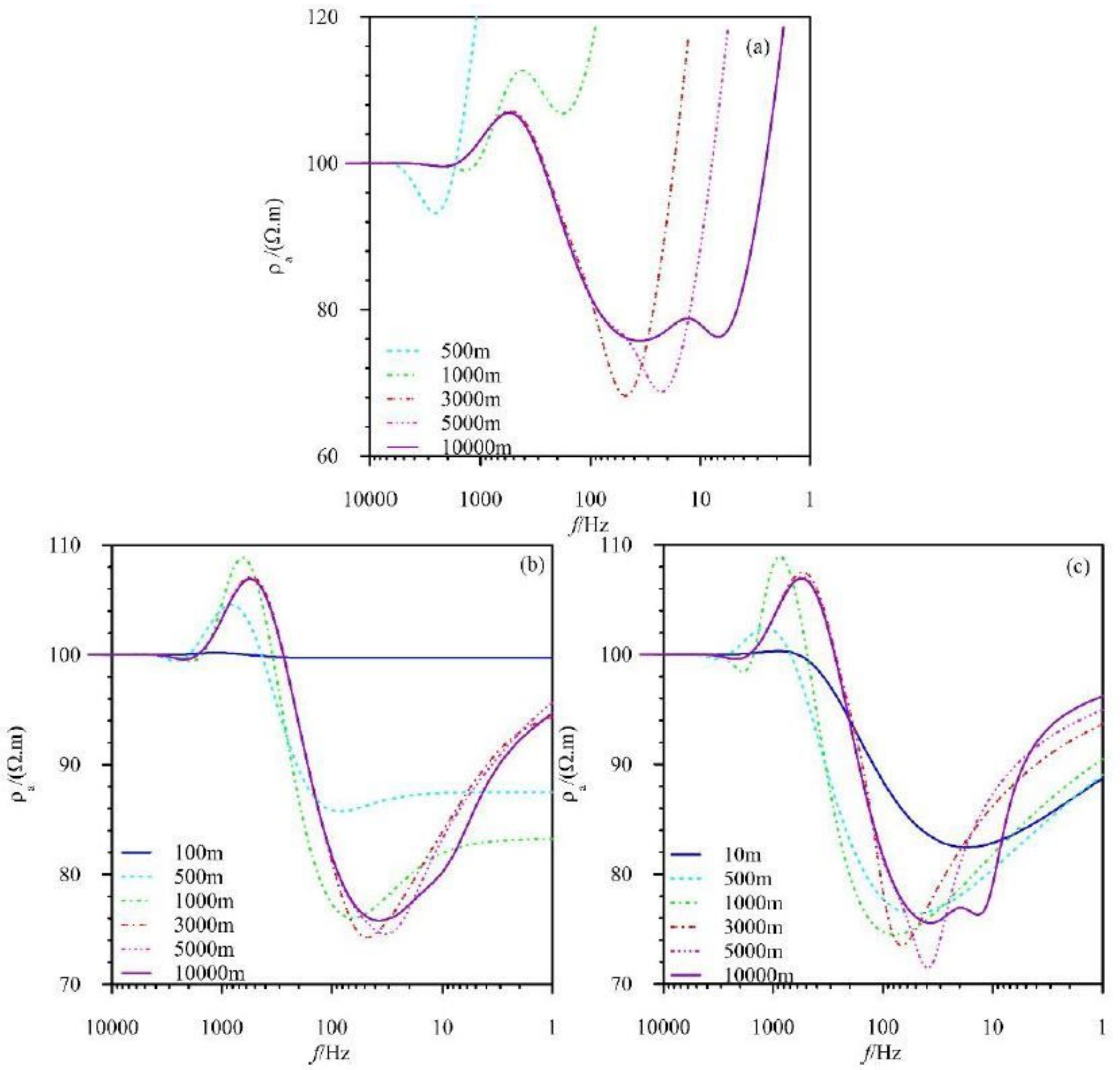

Figure 7

Comparison of different apparent resistivity curves at different offsets when the middle layer is conductive layer (a)Cagniard apparent resistivity curves (b)apparent resistivity curves based on Ex field (c) apparent resistivity curves based on $\mathrm{Hz}$ field 


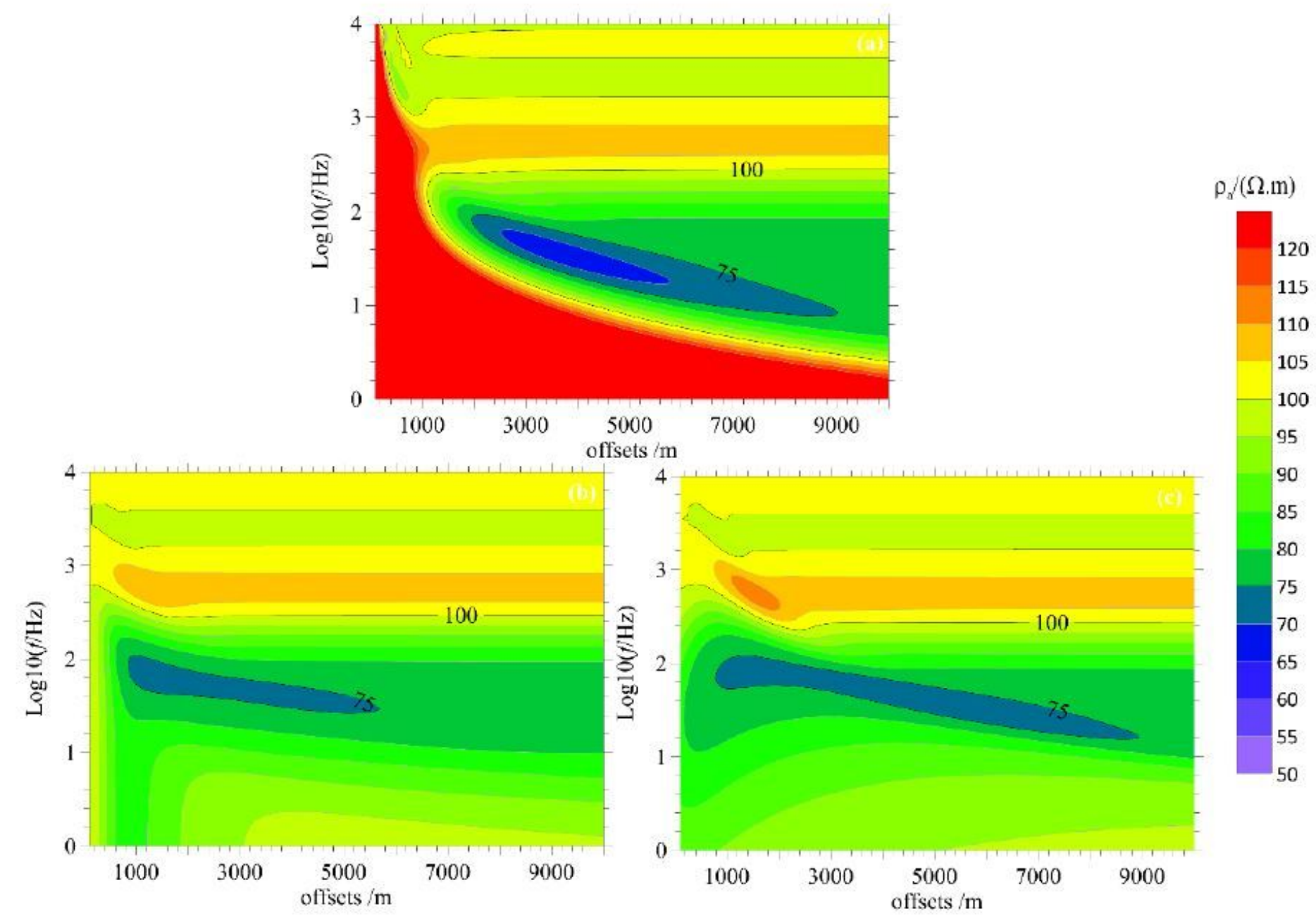

\section{Figure 8}

Comparison of apparent resistivity pseudo-section when the middle layer is conductive layer, the $x$-axis in the figure represents the offset, and the y-axis represents the logarithm of the frequency. (a) Cagniard apparent resistivity The data used to support the findings of this study are available from the corresponding author upon request. pseudo-section (b) apparent resistivity pseudo-section based on Ex field (c) apparent resistivity pseudo-section based on $\mathrm{Hz}$ field. 


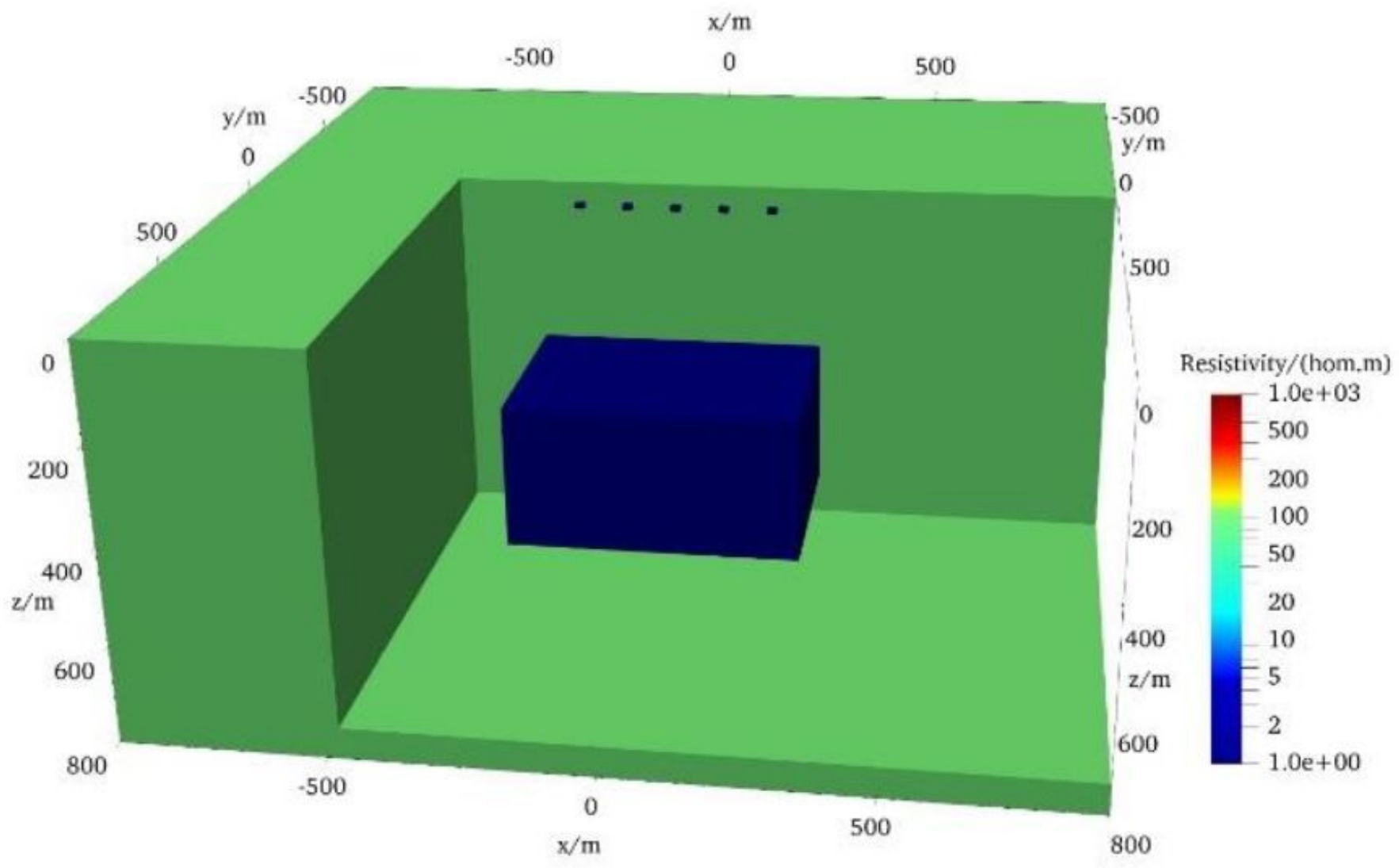

Figure 9

3D forward model with five anomalies in the shallows 


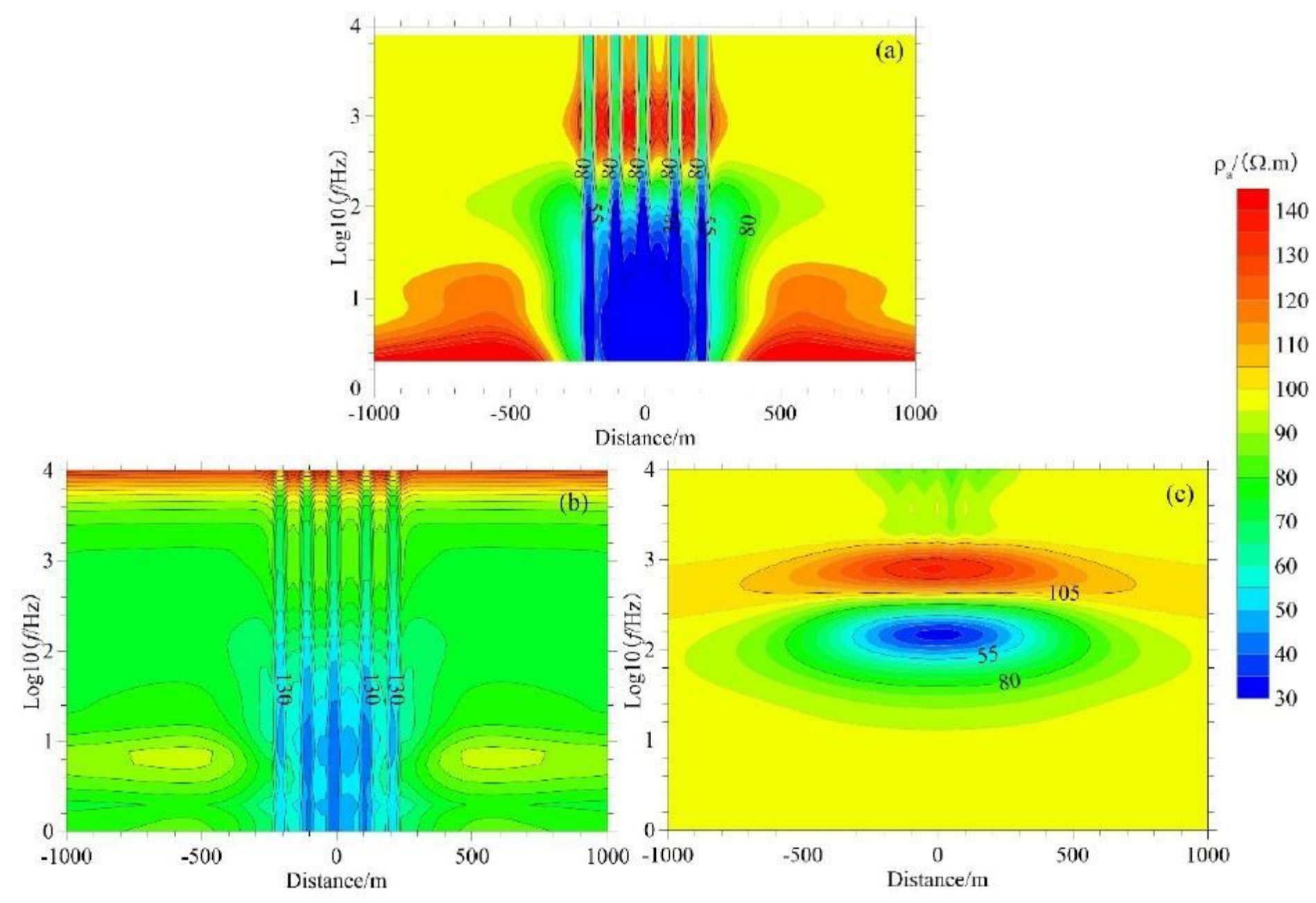

Figure 10

Apparent resistivity pseudo-section based on different fields (a) Cagniard apparent pseudo-section (b) apparent resistivity pseudo-section defined by Ex field (c) apparent resistivity pseudo-section defined by $\mathrm{Hz}$ field.
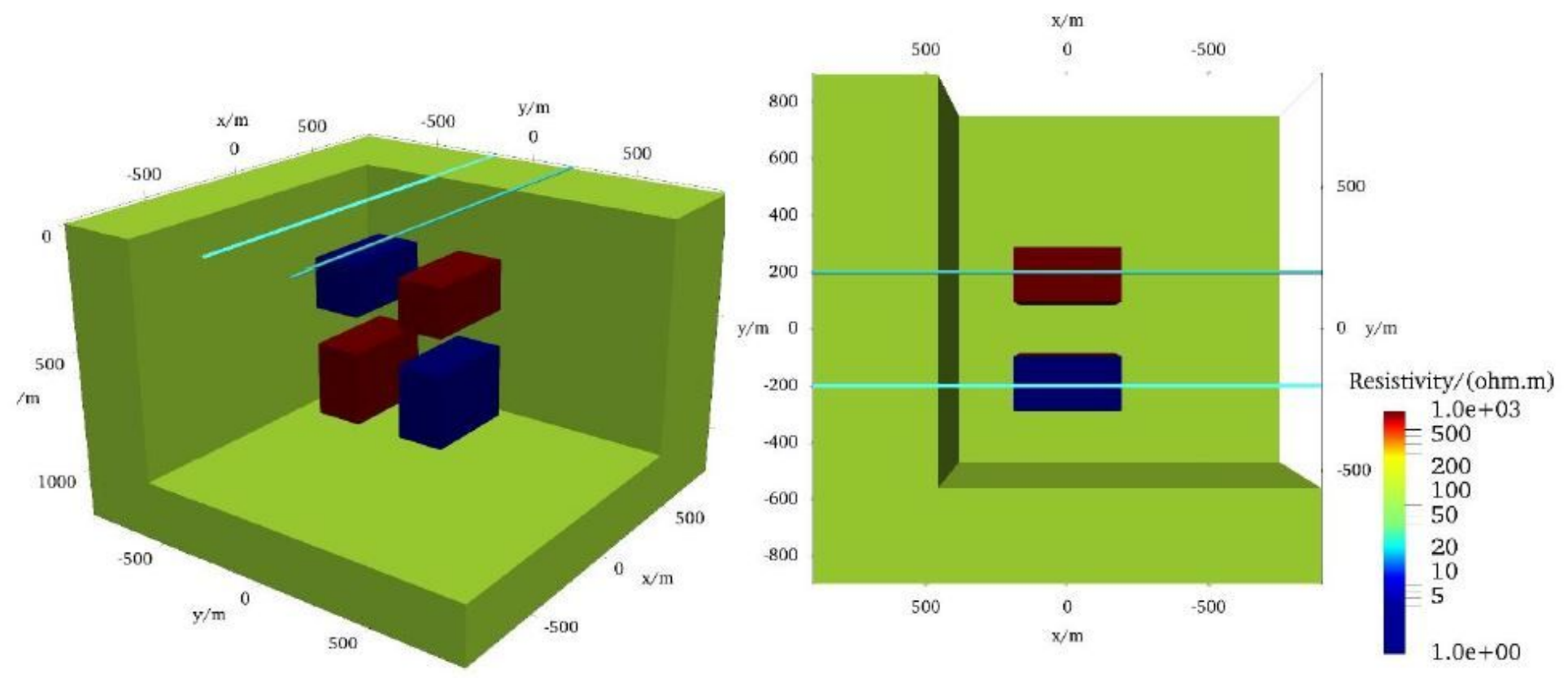


\section{Figure 11}

A more complex 3D forward model. The four anomalies are divided into conductive and resistance bodies, of which red represents resistance bodies with a resistivity of $1000 \mathrm{ohm} . \mathrm{m}$, and blue represents conductive bodies with a resistivity of $10 \mathrm{ohm} . \mathrm{m}$. The cyan lines are the designed exploration lines, which just pass through the center of the anomalous bodies.
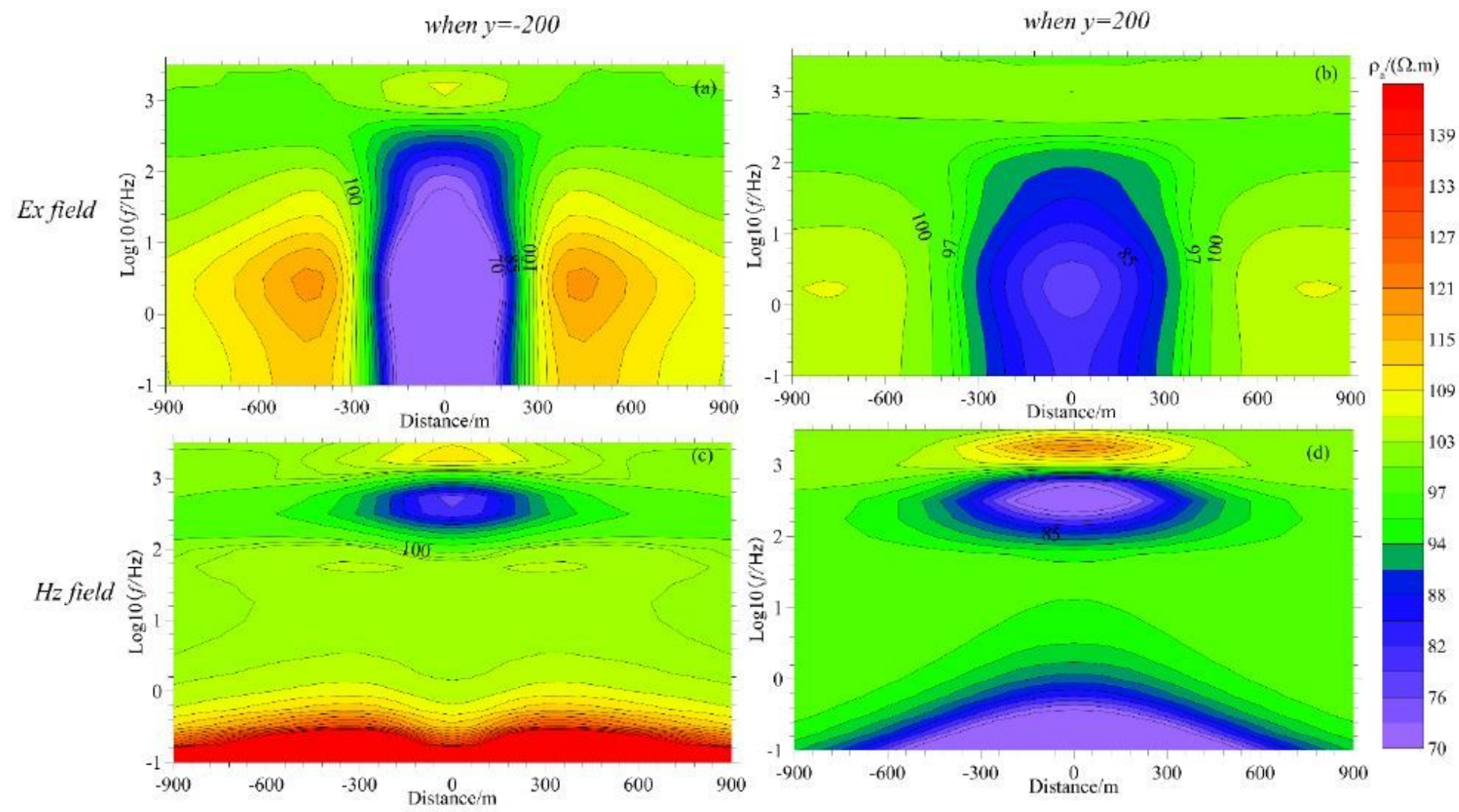

\section{Figure 12}

Apparent resistivity pseudo-section for both the Ex field and $\mathrm{Hz}$ field. The first row: Ex field, the second row: $\mathrm{Hz}$ field. The first column: $y=-200 \mathrm{~m}$, the second column: $y=200 \mathrm{~m}$. 


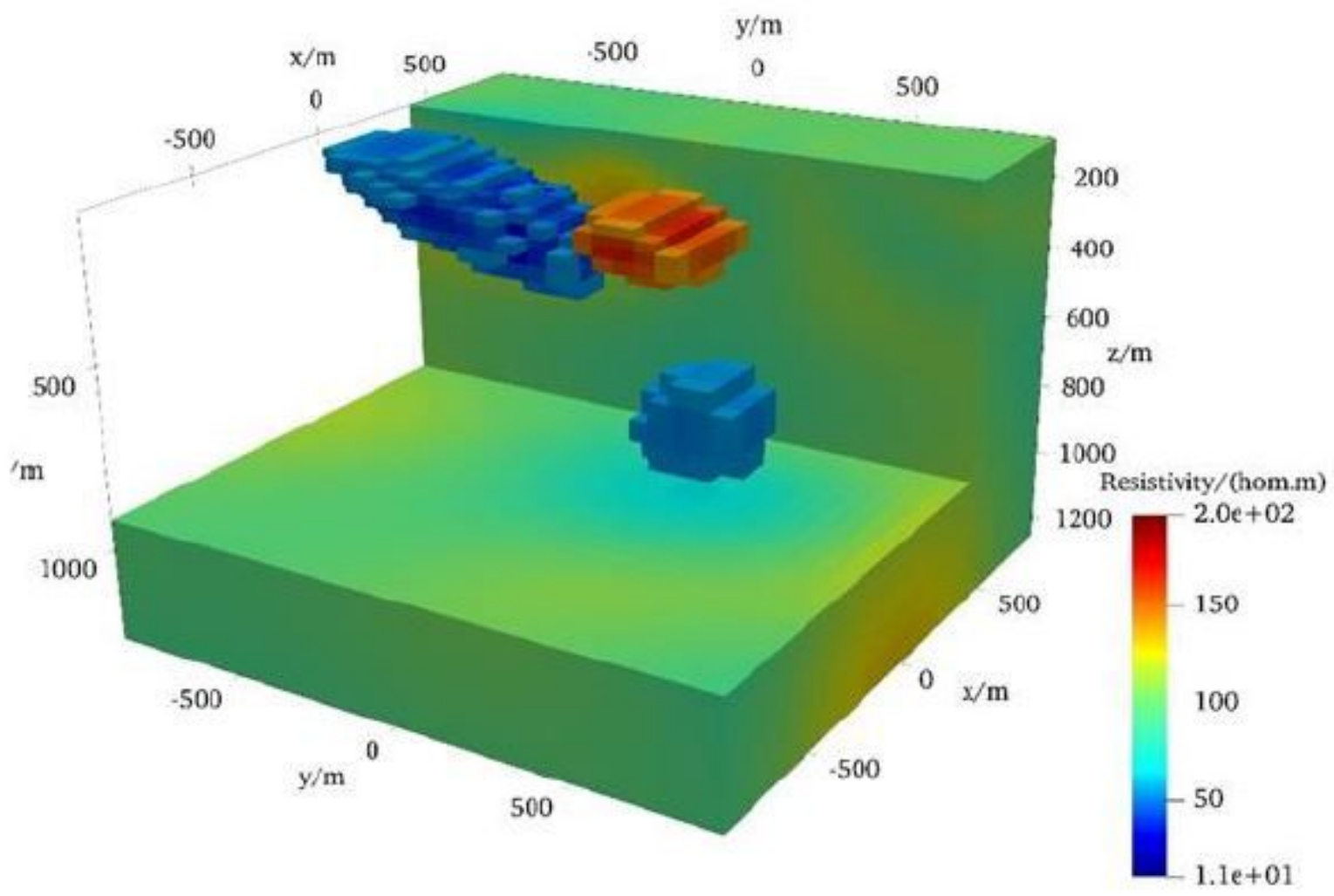

Figure 13

Slices of the recovered model from the 3D inversion of Ex field 